\title{
EL EMPLEO PRECARIO DE JÓVENES ASALARIADOS EN MÉXICO. EL CASO DE TOLUCA, TIJUANA Y MÉRIDA (2005-2010**
}

\author{
YULIANA GABRIELA ROMÁN SÁNCHEZ ${ }^{* *}$ \& DAVID CERVANTES ARENILLAS ${ }^{* * n}$ \\ EL COLEGIO DE MÉXICO
}

Recibido/ Received/ Recebido: 28/08/2012 - Aceptado/ Accepted / Aprovado: 07/05/2013

\begin{abstract}
Resumen
La globalización y la reestructuración productiva han configurado una nueva dinámica en los mercados de trabajo a nivel mundial. Este nuevo contexto laboral está caracterizado por la precarización de las condiciones laborales, fenómeno que no es exclusivo de algún sector de la población pero que los afecta de manera diferenciada, siendo los jóvenes uno de los grupos más vulnerables. El objetivo de este artículo es analizar las condiciones laborales de la población joven asalariada de tres ciudades mexicanas: Toluca, Tijuana y Mérida. Para ello, se estimó para estas tres ciudades un índice de precariedad laboral para el primer trimestre de 2005 y 2010. Los resultados muestran que la ciudad de Toluca registra una mayor proporción de jóvenes en empleos precarios, contra la ciudad de Tijuana donde se registran mejores condiciones laborales.

Palabras clave: Mercado de trabajo mexicano, Precariedad laboral, Empleo precario, Jóvenes asalariados, Ciudades mexicanas, Componentes principales.
\end{abstract}

\section{PRECARIOUS EMPLOYMENT OF YOUNG WORKERS IN MEXICO. TOLUCA, TIJUANA AND MERIDA CASE STUDIES (2005 - 2010)}

\begin{abstract}
Globalization and productive restructuration have set a new dynamic in labor markets worldwide. This new labor context is characterized by precarious labor conditions, phenomenon that is not exclusive of any population sector but affects them in a differential way, young people being the most vulnerable group. This article aim is to analyze the labor conditions of young workers population in three Mexican cities: Toluca, Tijuana and Merida. For this purpose, a precarious labor rate was estimated for all three cities for the first quarter of 2005 and 2010. Results show that Toluca city has the highest share of young people in precarious jobs, against Tijuana city where there are better conditions. Keywords: Mexican Labor Market, Job Insecurity, Precarious Employment, Young workers, Mexican cities, Main components.
\end{abstract}

Se presentan los resultados de la Tesis Doctoral: "Precariedad laboral de la población joven asalariada en México. Un estudio comparativo en tres ciudades: Toluca, Tijuana y Mérida, 2005 y 2010".

* Actuaria por la Universidad Autónoma del Estado de México (UAEMex), Maestra en Demografía por El Colegio de México y Candidata a Doctora en Ciencias Económico-Administrativas por la UAEMex. Ha participado como docente en El Colegio de México y en la Universidad Autónoma de Chiapas. Ha de colaborado en proyectos la Universidad Nacional Autónoma de México (UNAM), en el Consejo Nacional de Población (CONAPO), en la Secretaría del Trabajo y Previsión Social (STPS) y en el Programa de las Naciones Unidas para el Desarrollo (PNUD). Sus áreas de investigación son: la precariedad laboral de jóvenes, mortalidad y envejecimiento demográfico. Actualmente se encuentra como profesora de asignatura en la Facultad de Economía de la UAEMex. Correo electrónico: ygroman@colmex.mx

Licenciado en Economía Facultad de Economía Universidad Nacional Autónoma de México, Maestro en Demografía del Centro de Estudios Demográficos, Urbanos y Ambientales del El Colegio de México, estudiante Doctorado en Economía de la Universidad Nacional Autónoma de México. Correos electrónicos: dacervantes@colmex.mx, cervare@unam.mx. 


\title{
O EMPREGO PRECÁRIO DE JOVENS ASSALARIADOS NO MÉXICO. O CASO DE TOLUCA, TISUANA E MÉRIDA (2005 - 2010)
}

\begin{abstract}
Resumo
A globalização e a reestruturação produtiva configuraram uma nova dinâmica nos mercados de trabalho a nível mundial. Este novo contexto laboral está caracterizado pela precarização das condições de trabalho, fenômeno que não é exclusivo de um setor em especial da população, mas que os afeta a todos de maneira diferenciada, sendo os jovens um dos grupos mais vulneráveis. $\mathrm{O}$ objetivo deste artigo é analisar as condições laborais da população jovem assalariada de três cidades mexicanas: Toluca, Tijuana e Mérida. Para isso, estimou-se para estas três cidades um índice de precariedade laboral para o primeiro trimestre de 2005 e 2010. Os resultados mostram que a cidade de Toluca registra uma maior proporção de jovens em empregos precários, em relação à cidade de Tijuana onde se registram melhores condições de trabalho.

Palavras chave: Mercado de trabalho mexicano, Precariedade de trabalho, Emprego precário, Jovens assalariados, Cidades mexicanas, Componentes principais.

Román, Y. \& Cervantes, D. (2013) El empleo precario de jóvenes asalariados en México. El caso de Toluca, Tijuana y Mérida, 2005 y 2010. En: Revista de la Facultad de Ciencias Económicas de la Universidad Militar Nueva Granada. rev.fac.cienc.econ, XXI (1)
\end{abstract}

JEL: J01, J81, C38

\section{Introducción}

La gran inestabilidad económica a nivel mundial que se presentó desde finales de la década de 1970, ha provocado una serie de transformaciones en la estructura y organización productiva de los países. Bajo el lema de hacer frente a las crisis económicas y poder elevar la productividad, las empresas han impulsado cambios orientados a operar de manera más intensiva y con mayor flexibilidad laboral.

Este proceso de flexibilización junto con la incapacidad de superar el estancamiento económico y el rápido crecimiento de la población han impactado de manera negativa en la creación de empleos, provocando una alta segmentación en los mercados de trabajo, que han ubicado a una gran masa de población ocupada en el sector informal, en la subocupación y en el desempleo, lo cual ha tenido un efecto desfavorable sobre las condiciones de trabajo. Por lo anterior, en el presente artículo se plantean las siguientes preguntas de investigación: ¿cómo se puede estimar el impacto del proceso de precarización de las condiciones laborales de la población joven asalariada? ¿Cuáles son las condiciones de empleo de la población joven asalariada en las ciudades de
Toluca, Tijuana y Mérida? y ¿Cuál ciudad ha sido la más afectada por este fenómeno?

Con la finalidad de responder estas interrogantes, el documento comienza con un recorrido conceptual sobre diferentes modalidades de la relación laboral; y se aborda el fenómeno de la precariedad laboral y su relación con la población joven asalariada en tres ciudades de México: Toluca, Tijuana y Mérida. Para el análisis se toma de referencia la información de la Encuesta Nacional de Ocupación y Empleo (ENOE), a partir de la cual se realiza una operacionalización del concepto de empleo precario, así como la construcción y estratificación de un índice de precariedad laboral a través de métodos de análisis multivariado. En los resultados se exponen los diferentes niveles de empleo precario de la población joven asalariada de Toluca, Tijuana y Mérida para 2005 y 2010, y por último se presentan las conclusiones.

\section{El concepto de precariedad laboral y empleo precario}

Bajo el argumento de que las rigideces del mercado de trabajo obstaculizan el crecimiento económico y la generación de empleos, se llevaron a cabo una 
serie de reformas tendientes a flexibilizar el mercado de trabajo. Este proceso de flexibilización de acuerdo a la teoría económica permite a las empresas adaptarse de forma rápida ante cambios de la demanda, por lo cual elimina las restricciones al crecimiento y fomenta la competitividad.

La flexibilización laboral fue la respuesta al hecho de suponer que las empresas por su tamaño, se habían vuelto ineficaces y de esta manera les permitiría responder de manera rápida y eficaz a las fluctuaciones del mercado, bajando costos y facilitando la movilidad de los trabajadores, lo que repercutiría de manera positiva sobre los niveles de productividad de las empresas y les permitiría operar de manera más intensiva y eficiente. En la práctica, la flexibilidad en el mercado de trabajo se puede identificar bajo los siguientes rasgos (Rifkin \& Heilbroner, 1996):

a) Flexibilidad interna o funcional en el uso de la mano de obra, que consiste en la adaptabilidad de los trabajadores a variaciones $\mathrm{y} / \mathrm{o}$ reducción de los turnos, jornadas, horas extra, movilidad geográfica y polivalencia de los trabajadores.

b) Flexibilidad externa o numérica cuyo objetivo es modificar los volúmenes del empleo acorde a las fluctuaciones del mercado, a través de modificaciones legales y administrativas promoviendo las formas de empleo "atípico", como los contratos temporales, de duración determinada, de formación, por obra o servicio, entre otras.

c) Flexibilidad productiva interna enfocada a modificar la organización del sistema de producción introduciendo nuevos mecanismos como las Tecnologías de Información o Comunicación (TICs), modificando los sistemas de proveeduría y almacenamiento tendientes a la producción just in time, etc.

d) Flexibilización productiva externa que se vincula con la externalización de las partes del proceso productivo o de segmentos completos de la empresa a través de la subcontratación, trabajo autónomo, entre otros. Esta modalidad permite emplear a trabajadores con salarios más bajos, temporales y que no guardan una relación jurídica con la empresa en la que realizan sus actividades. e) Flexibilidad salarial, la cual se vincula a los resultados de la empresa, es decir, los salarios varían en función del desempeño global de la unidad económica y están sujetos a movimientos externos coyunturales.

Sin embargo, la flexibilización del mercado de trabajo no ha generado efectos homogéneos y positivos; en la mayoría de los países latinoamericanos este proceso junto con otros fenómenos como el declive del empleo público, la migración internacional, la persistencia de la pobreza, el desempleo y la destrucción del empleo asalariado, han sido determinantes en el surgimiento de nuevas formas de empleo atípicas como el trabajo sin contrato, temporal, por cuenta propia, subcontratado, a domicilio, entre otras; dando paso al auge y prevalencia del empleo precario.

Cabe señalar que la precariedad laboral no es un fenómeno cuyo origen se ubique en el proceso de flexibilización laboral, sin embargo, es a partir de estas transformaciones cuando se manifestó con mayor intensidad. En el nuevo contexto económico, la precariedad laboral constituye el patrón que describe las nuevas formas de contratación y uso de la mano de obra, como resultado de las diferentes estrategias empresariales impuestas a partir de la reestructuración productiva y la flexibilidad laboral.

El término de precariedad laboral se ha ido popularizando porque es un fenómeno que se ha extendido en las diferentes modalidades de inserción ocupacional y que se ha reproducido en diversos países, como resultado del proceso de globalización económica. De hecho, el fenómeno de precariedad laboral se ha convertido en un elemento fundamental para explicar y comprender el actual funcionamiento de los mercados de trabajo, cuyos rasgos constituyen, además, un factor importante para explicar formas de pobreza, vulnerabilidad y exclusión social (García, 2001; Ferreira, 2006; Mora, 2006; De Oliveira, 2006).

Si bien, la precariedad describe de manera general el deterioro de las condiciones laborales de los trabajadores, su significado ha sido conceptualizado de diferentes maneras como: "fragmentación" 
(Offe, 1992), "individualización" (Castel, 1994), "desafiliación" (Castel, 1995), "flexiprecarización" (Sotelo, 1997), entre otros. Esto nos da pauta para señalar que no existe una definición única para denominar a la precariedad laboral. A pesar de ello, diversos autores coinciden en que la precariedad es sinónimo de malas las condiciones laborales, causadas por el establecimiento de la relación laboral en condiciones poco favorables para el trabajador. Así la precariedad puede adoptar características tales como: el empleo a tiempo parcial, sin beneficios sociales, con inestabilidad en la jornada de trabajo y otras formas (Rojas \& Salas, 2007).

Para otros autores, el fenómeno de precariedad laboral está destinado a mostrar los problemas que enfrentan sólo los trabajadores asalariados, independientemente del sector, tipo y tamaño de empresa donde se ubiquen, ocupación que desarrollen, sexo del trabajador y nivel de escolaridad, aunque sí con algunos matices. De manera que los trabajadores asalariados se han visto afectados por bajos salarios, sin contrato laboral, prolongación desmedida de las jornadas de trabajo y, sobre todo, en el deterioro de sus derechos laborales (Sotelo, 1998; Castillo, 2001; De Oliveira, 2006).

Partiendo de estas diferentes concepciones en esta investigación se entiende por precariedad laboral al deterioro de las relaciones y condiciones laborales que se dan como consecuencia del proceso de reestructuración productiva y de la flexibilización laboral, fenómeno que lleva al debilitamiento del trabajo como uno de los determinantes básicos de integración y movilidad social y, que expone a amplios sectores de la población asalariada a la vulnerabilidad; siendo el grupo de los jóvenes el más afectado.

El mercado de trabajo contemporáneo está caracterizado por la presencia del empleo precario, sin embargo, actualmente no existe una teoría que logre conceptualizarlo de manera generalizada (Carty, 1999; Castillo, 2009), ya que depende u obedece a diversas particularidades económicas, sociales, culturales, políticas e históricas de cada país o región ${ }^{1}$.

Por lo anterior, es necesario definir y delimitar lo que se considera por empleo precario ya que con frecuencia se suelen confundir conceptos como trabajo/empleo precario; trabajo/empleo no registrado y trabajo/empleo informal que se refieren a realidades diferentes pero que en sentido amplio las tres modalidades pueden definirse como de carácter precario (Neffa, 2010). En este sentido, la principal diferencia entre trabajo y empleo radica en que por el primero se entiende como el esfuerzo humano aplicado a la transformación de recursos en satisfactores para las necesidades de los individuos y de sus sociedades (Noriega, 2009); el trabajo se vuelve empleo o también llamado trabajo asalariado cuando la persona que lo realiza recibe a cambio un sueldo o un salario, entonces el individuo se vuelve subordinado de manera formal, dependiente, heterónomo o en relación de dependencia y es llamado asalariado.

El trabajo precario se evidencia en las actividades económicas informales pero también en las formales; mientras que el empleo precario se refiere a la inseguridad, la inestabilidad de la relación salarial sólo en el sector formal de la economía y lo evidencia la población asalariada; mientras que los empleos precarios son generalmente lícitos establecidos válidamente por leyes o decretos, aunque tengan repercusiones negativas sobre el sistema de relaciones de trabajo, los empleos asalariados no registrados tienen un carácter de ilegal (Neffa, 2010).

Por su parte, el trabajo no registrado está más asociado al trabajo informal. Desde la definición de Organización Internacional del Trabajo (2003), los trabajadores que no están sujetos a la legislación laboral forman la categoría de trabajadores no registrados, independientemente de si se desempeñan en el sector formal o informal de la economía. Esta situación existía desde hace tiempo en el sistema productivo, pero este tipo de traba-

1 La noción de calidad del empleo es un concepto más amplio que el de empleo precario, este último es una derivación del primero, que incluye diversas dimensiones del mercado laboral y su dinámica interna (Castillo, 2009). 
jadores no habían sido reconocidos o integrados dentro del concepto de informalidad. El empleo no registrado "en negro" (Neffa, 2010) es aquel que sin ser ilícito no está declarado a las autoridades que deberían tener conocimiento de él, y por ese hecho, se sustrae de la reglamentación y de los impuestos, lo anterior conduce a una reducción de las prestaciones de la seguridad social. Los elementos esenciales de la informalidad y la precariedad no son idénticos, aunque pueden darse de manera conjunta, sin embargo el carácter de legal o ilegal no es una característica necesaria y esencial del trabajo informal, pero se pueden dar de forma complementaria, por ello autores como De Soto (1987) y Tokman (2004) mencionan que las actividades ilícitas como: narcotráfico, contrabando, trata de esclavos, niños o mujeres deberían excluirse de la definición de trabajo informal (Neffa, 2010). El presente documento no pretende realizar una conceptualización exhaustiva de las diferentes relaciones laborales, sino más bien centrarse en la esencia del fenómeno de precariedad laboral, que es el empleo precario, pero sin olvidar que existen otras formas que no son idénticas a éste.

La OIT (2002) concibe al empleo precario como la relación laboral donde falta la seguridad de empleo, uno de los elementos principales del contrato de trabajo, término que comprende el contrato temporal, ocasional, a corto plazo, estacional, a tiempo fijo, trabajo a domicilio y la subcontratación (OIT, 2002). En este mismo sentido, estudios empíricos anteriores han conceptualizado al empleo precario de diversas maneras, que van desde una perspectiva jurídica y opuesta al empleo típico, tradicional o estándar, es decir, como aquel empleo desarrollado antes del agotamiento del fordismo (Caire, 1982; Córdova, 1985; Rodger, 1989), a definiciones muy concretas de acuerdo a un contexto nacional o regional (Rubery, 1989), o considerando el cumplimiento o no de la regulación del Estado sobre las condiciones laborales (Marshall, 1992), poniendo atención sólo al tipo de contrato como factor determinante (Guerra, 1994), haciendo referencia a la pérdida de los derechos contractuales, jurídico laborales y normas protectoras de trabajo (Sotelo, 1997; Castel, 2003), o aludiendo a las nuevas relaciones entre capital y trabajo que impiden a los trabajadores ejercer sus derechos laborales básicos (Mora, 2010).

El conjunto de definiciones converge a que en los mercados de trabajo existe una nueva situación laboral llamada: empleo precario, como consecuencia de las nuevas formas de contratación dentro del contexto de la globalización económica y los procesos de flexibilización laboral, introducidos con la reestructuración productiva y las estrategias de las empresas para reducir los costos de mano de obra.

El empleo precario se constituye como el aspecto central del estudio, conceptualizado a partir de tres dimensiones: la económica, que implica la disponibilidad de trabajo e ingresos adecuados; la normativa, que se refiere a la promoción de los derechos del trabajador y la seguridad laboral, que atañe a las necesidades de garantizar la protección social del trabajador (De Oliveira, 2006).

A partir de estas dimensiones, en el concepto de empleo precario se toman en cuenta las condiciones laborales de los trabajadores asalariados, donde sus derechos laborales básicos por pertenecer al sector formal de la economía se ven afectados, los cuales resultan insuficientes para tener una vida decorosa, con ingresos que no cubren sus necesidades básicas, afectados por la ausencia de prestaciones laborales a las que tienen derecho y sin seguridad social. Esta definición que se propone hace referencia sólo a las condiciones laborales bajo las cuales se encuentran los asalariados y no a las características que poseen o no los trabajadores.

Investigaciones previas muestran que la presencia de empleo precario no es un evento exclusivo de algún país, sector económico, empresa o sólo de los mercados de trabajo informales, en otras palabras, cualquier trabajador es propenso a tener un empleo precario, sin embargo, no necesariamente los afecta de la misma manera. De forma consensada los grupos de trabajadores con mayor grado de vulnerabilidad a tener un empleo precario son los jóvenes, las mujeres y los migrantes.

Para Navarrete (2002), De Oliveira (2006) y Mora (2010) los jóvenes conforman el grupo más sensible 
para insertarse y permanecer en el mercado laboral como mano de obra barata, flexible y precaria, porque es vista con poca o nula experiencia laboral, con alto nivel de productividad $y$, en muchos casos con bajo nivel de escolaridad o escolaridad trunca. Por lo anterior, los jóvenes asalariados de 14 a 29 años constituyen nuestra población objetivo para analizar el fenómeno de precariedad laboral. Asimismo, se ha decidido centrar nuestra atención en los asalariados debido a que el interés de este artículo se enfoca en analizar, exclusivamente, el segmento más estructurado de la economía que es el sector formal, donde los trabajadores perciben por parte de la unidad económica a la que pertenecen un sueldo, salario o jornal por su trabajo. Pero que al mismo tiempo este sector ha sido el más afectado por diversas políticas económicas de abaratamiento de la mano de obra como el control salarial y la disminución de la protección social de los trabajadores, esto para lograr una mayor competitividad en los mercados internacionales.

Al respecto, Mora \& De Oliveira (2009) mencionan que el deterioro de las condiciones laborales de los asalariados se debe, entre otros aspectos, a la apertura comercial y al aumento de las importaciones que han traído consigo el desmantelamiento de la industria nacional, cada vez menos competitiva, y una disminución en la creación de empleos por parte de las empresas de mayor tamaño, productividad y competitividad, así como a los programas de estímulo a los micronegocios. Se suman a estos factores otros como las políticas de contracción del Estado que han favorecido la erosión del poder de integración social, así como a la pérdida del poder de negociación de los sindicatos.

El deterioro de las relaciones y condiciones laborales que enfrentan los jóvenes es un fenómeno de escala mundial, debido a que existen limitadas oportunidades disponibles para que los jóvenes puedan incorporase al mercado de trabajo, situación que se complica cuando los vínculos familiares no existen, porque ellos quedan más expuestos al riesgo de abandonar la escuela a temprana edad y de ser explotados al incorporarse al mercado de trabajo, además de ser los más vulnerables ante el ciclo económico (OIT, 2004; OIT, 2005; Weller, 2006).
En México, la situación del empleo precario para la población joven es alarmante (Navarrete, 2001; Aranda, 2005; De Oliveira, 2006), el uso de este tipo de mano de obra coincide con afirmaciones de autores como Castel (1998) y Mora (2006) que el proceso de la globalización económica constituye un rasgo estructural del modelo económico, que recurre a la desregulación del mercado de trabajo para reducir los costos de producción mediante el abaratamiento de la mano de obra y el aumento de la productividad.

El trabajo juvenil se ve afectado, además de los bajos ingresos, por la escasa seguridad laboral y la falta de prestaciones sociales, elementos fundamentales para las condiciones de vida, que si bien no es exclusivo de la población joven, tales condiciones afectan en mayor medida a los jóvenes que a los adultos, además, desarrollan actividades de poca jerarquía y su nivel de participación laboral se reduce en las crisis económicas (Navarrete, 2001; Camarena, 2004).

En el marco de la globalización económica, el grupo de población joven ha tenido que adaptarse a la nueva situación del mercado laboral, los jóvenes que logran insertarse y permanecer en él, lo hacen bajo condiciones precarias, pues los mercados laborales no ofrecen grandes opciones laborales (Navarrete, 2000). Con esto, las empresas han resultado beneficiadas al sustituir mano de obra madura por trabajadores jóvenes y en algunos casos con mejores niveles de instrucción. Por ello, las nuevas políticas empresariales, con la premisa de la reducción de costos dan cabida en su plantilla de trabajadores a la población joven por constituir un grupo con mayor facilidad de explotación.

Prueba de esta problemática laboral se corrobora con la creciente cantidad de estudios y publicaciones sobre las malas condiciones laborales, desempleo y subempleo juvenil que muestran evidencias de las dificultades de empleo por las que atraviesan los jóvenes, no sólo el presente suscita esa preocupación; los próximos años, al parecer estarán marcados por el desempleo, la subcontratación y evidentemente por la precariedad laboral. 


\section{Dimensiones del empleo precario: unapropuestadeestimaciónparaMéxico}

En un inicio se suponía que la precariedad de las condiciones laborales era característica de los países subdesarrollados, sin embargo en los últimos años este fenómeno se ha ido imponiendo también en los países industrializados, de acuerdo con Castillo (2001) ha sido impulsado por el proceso de globalización económica, el cual ha impuesto una nueva división territorial del trabajo a escala internacional que se caracteriza por una desvalorización territorial del trabajo, es decir, cuanto más lejos, física y socialmente, está la empresa peores son las condiciones de trabajo (Morales \& Villarino, 2007).

En México, la noción de precariedad laboral y el empleo precario han adquirido relevancia en los últimos años. El primer acercamiento al tema de precariedad laboral aparece en Rendón \& Salas (1992), donde se discute el impacto de los bajos salarios. En Salas (2000) se encuentra un avance en la discusión teórica y empírica, mientras que García \& De Oliveira (2001a, 2001b) realizan una discusión sistemática de la calidad de los empleos durante la década de los noventa, cubriendo algunos elementos de la precariedad laboral como ingresos, prestaciones y jornada de trabajo (Rojas \& Salas, 2007).

En este estudio se conceptualiza a la precariedad laboral en función del empleo precario a partir de tres dimensiones: económica, normativa y seguridad laboral. Como se muestra en la Tabla 1, cada una de estas dimensiones establece criterios para definir y diferenciar niveles de empleo precario de los trabajadores con base en siete indicadores. En el caso de la dimensión económica se toma como base el salario mínimo, el cual debe ser suficiente para cubrir las necesidades de los trabajadores como: alimentación, calzado, vestido, etc., por lo anterior, cuando el salario no logra satisfacer esas necesidades básicas los jóvenes se ubicarán en una situación de precariedad ${ }^{2}$.

Para la dimensión normativa se considera al contrato como un elemento fundamental que garantiza la protección a los trabajadores, la duración de los contratos: temporales o estables, así como las jornadas laborales incompletas $e$ inestables que desprotegen a los trabajadores haciéndolos vulnerables y por lo tanto con empleos precarios.

La seguridad social y las prestaciones laborales juegan un papel fundamental para asegurar el bienestar de los trabajadores, por ello cuando los trabajadores carecen de estos, precarizan sus condiciones laborales. La pertenencia sindical es fundamental para garantizar la representación a los trabajadores, ya que brinda poder de negociación y garantiza el diálogo con los empleadores, en este sentido, un bajo nivel de representatividad también tiene implicaciones directas sobre los niveles de empleo precario. Estos aspectos conforman la dimensión de seguridad laboral.

Vale la pena aclarar que cuatro indicadores (salario mínimo, duración de la jornada de trabajo, duración del contrato y seguridad social) se tomaron como referencia de las investigaciones de Mora (2006, 2010). Sin embargo, el mismo autor recomienda que para futuras investigaciones sería conveniente agregar algún(os) indicador(es) con el propósito de mejorar el análisis de la precariedad laboral. Basados en esos indicadores y en la revisión de literatura, para esta investigación se integraron tres indicadores más que son: prestaciones sociales, afiliación al sindicato y tipo de contrato. La inclusión de las prestaciones sociales se hizo con base en las recomendaciones de Sotelo (1999), Castillo (2001), De Olivera (2006); la afiliación al sindicato se tomó de García (2006); y el tipo de contrato fue a partir de las investigaciones de De Oliveira (2006) y Castillo (2009).

2 En esta investigación se considera empleo precario cuando el ingreso es menor a dos salarios mínimos debido a que este número de salarios resulta insuficiente para satisfacer, abastecer y solventar las necesidades de la canasta básica de una familia (Gutiérrez, 1999; Mora \& De Oliveira, 2009). 
Tabla 1. Precariedad laboral: Dimensiones, conceptos y criterios ${ }^{3}$

\begin{tabular}{|c|c|c|c|}
\hline Dimensión & Conceptualización & Indicador & Criterios \\
\hline 1. Económica & Ingresos suficientes & a. Salario mínimo & $\begin{array}{l}\text { - Se considera precario cuando el salario es menor al } \\
\text { que garantiza un nivel mínimo necesario para tener } \\
\text { acceso a alimentación, vestido, educación, salud y } \\
\text { vivienda. }\end{array}$ \\
\hline 2. Normativa & $\begin{array}{l}\text { Promoción de los } \\
\text { derechos del } \\
\text { trabajador }\end{array}$ & $\begin{array}{l}\text { b. Contratos de trabajo } \\
\text { c. Temporalidad } \\
\text { d. Duración de jornada }\end{array}$ & $\begin{array}{l}\text { - Las relaciones de trabajo sin contrato vulnera y } \\
\text { desprotege a los trabajadores. } \\
\text { - La temporalidad como un fenómeno de inestabilidad } \\
\text { laboral. } \\
\text { - Jornada laboral completa, estable y remunerada } \\
\text { garantiza buenas condiciones a los trabajadores, por lo } \\
\text { anterior, jornadas inestables e incompletas precarizan las } \\
\text { condiciones de los trabajadores. }\end{array}$ \\
\hline \multirow{3}{*}{$\begin{array}{l}\text { 3. Seguridad } \\
\text { laboral }\end{array}$} & \multirow{3}{*}{$\begin{array}{l}\text { Protección social del } \\
\text { trabajador }\end{array}$} & e. Acceso a la seguridad social & $\begin{array}{l}\text { - La falta de acceso a la seguridad social precariza las } \\
\text { condiciones de trabajo. }\end{array}$ \\
\hline & & f. Prestaciones sociales & $\begin{array}{l}\text { - Prestaciones laborales como un elemento que mejora } \\
\text { las condiciones de trabajo. Un bajo nivel de prestaciones } \\
\text { contribuyen a fomentar la precariedad laboral. }\end{array}$ \\
\hline & & g. Nivel de sindicalización & $\begin{array}{l}\text { - El bajo nivel de sindicalización actúa en detrimento de } \\
\text { la representatividad de los trabajadores y en su poder de } \\
\text { negociación. }\end{array}$ \\
\hline
\end{tabular}

Con la integración de estos siete indicadores se pretende analizar de forma integral el fenómeno de precariedad laboral. Además, estos indicadores permiten analizar la diversidad de condiciones laborales de los jóvenes asalariados y clasificarlos en un primer momento situación de empleo precario y no precario; y a partir de ahí encontrar diferentes intensidades en el deterioro de las condiciones laborales.

\section{Las dimensiones del empleo precario para el caso de los jóvenes asalariados de las ciudades de Toluca, Tijuana y Mérida, 2005 y 2010}

Este apartado tiene como finalidad analizar las dimensiones del empleo precario partiendo de los indicadores que integran las dimensiones de la precariedad laboral. El análisis se realiza de manera comparada para la población joven asalariada (14 a 29 años) de las tres ciudades seleccionadas: Toluca, Tijuana y Mérida. Estas ciudades se caracterizan por tener un alto dinamismo económico, diferentes niveles de competitividad y especialización productiva diferenciada.

De acuerdo a la información del Censo Económico 2009 que muestra la Tabla 2, la participación del
Valor Agregado Bruto del sector industrial de las ciudades de Toluca y Tijuana es mayor al promedio nacional. En el caso de la ciudad de Mérida el sector servicios es 20 por ciento mayor al nacional, lo que refleja la especialización productiva antes mencionada.

La ciudad de Toluca funge como la ciudad central de la Zona Metropolitana de Toluca (ZMT), misma que comenzó a cobrar importancia a nivel nacional en 1990 (Aranda, 2005). Para el año 2005, la ZMT ocupó, por el tamaño poblacional, el quinto lugar dentro de las 56 zonas del país. Esta zona constituye por su cercanía con la Zona Metropolitana de la Ciudad de México (ZMCM) y con el corredor Golfo-Pacífico un sistema complejo de relaciones demográficas, económicas, sociales, políticas, culturales y territoriales de gran dimensión (Martínez, 2008).

En Toluca, el sector secundario fue, aproximadamente, por tres décadas el principal receptor de mano de obra. La Población Económicamente Activa (PAE) pasó de 21,4 en 1950 a 33,6 por ciento en 1990 y 32,5 en el año 2000 (Rodríguez, 1994; INEGI, 2000). Sin embargo, en los años recientes se ha evidenciado una reducción de tal situación.

3 Fuente: Elaboración propia con base en Sotelo (1999), Castillo (2005), De Olivera (2006), García (2006) y Mora (2010). 
Tabla 2. Valor Agregado Censal Bruto: Nacional, Tijuana, Toluca y Mérida. ${ }^{4}$

\begin{tabular}{lcccc}
\hline Sector / VA & Nacional & Toluca & Tijuana & Mérida \\
\hline Valor Agregado Censal Bruto & $373,736.0$ & $5,769.0$ & $4,744.0$ & $2,509.6$ \\
(Millones de dólares) & $100 \%$ & $100 \%$ & $100 \%$ & $100 \%$ \\
\hline Agrícola & $0.2 \%$ & - & $0.04 \%$ & - \\
Industrial & $57.9 \%$ & $83.2 \%$ & $59.6 \%$ & $38.0 \%$ \\
Servicios & $41.9 \%$ & $16.8 \%$ & $40.4 \%$ & $62.0 \%$ \\
\hline
\end{tabular}

Dentro de este sector destaca, por el personal ocupado, la industria manufacturera como: automotriz, alimentos, bebidas y tabaco y química (Rodríguez, 1994; Aranda, 2005).

En este sentido, el desarrollo industrial de Toluca, basado en el sector secundario, fue en un principio generador tanto de demanda como de oferta de trabajo. No obstante, este desarrollo dio un gran impulso al crecimiento del sector de los servicios, mismo que en la actualidad representa la oferta de trabajo más dinámica y creciente. El desarrollo industrial tuvo un efecto multiplicador en la demanda de los servicios, tanto en la ciudad de Toluca como en los municipios aledaños (Rodríguez, 1994).

Bajo este contexto, el sector terciario aumentó la generación de empleos en las últimas décadas. En 1950, la PEA representaba 32,1 por ciento de total de la PEA de la ciudad, y pasó a 59,4 en 1990, a 61,4 en el año 2000. Esta terciarización experimentada en la economía toluqueña, y en general en todo el país es, en buena medida, resultado de la búsqueda de alternativas por parte de la población de áreas rurales, que migraron a la ciudad con la intensión de mejorar sus condiciones de vida (Rodríguez, 1994; INEGI, 2000). El mayor porcentaje de establecimientos de servicios corresponden a restaurantes, bares, centros nocturnos, así como los servicios de reparación, médicos, personales y profesionales, el conjunto de estos servicios representaron en el año 2000, el 90 por ciento de los servicios censados (Aranda, 2005).

Bajo este tenor, la ciudad de Toluca constituye, actualmente, un centro de atracción económica por la interrelación física con la carretera de cuota Toluca-
México y, también por la vía aérea con el Aeropuerto Internacional, así como por el tamaño de sus mercados y la complementariedad de sus servicios con la Ciudad de México. La ciudad de Toluca ha presentado una mayor expansión física y, con ello ha atraído la inversión de capital nacional y extranjero, por ello se consolida cada vez más como una ciudad proveedora de productos y servicios nacionales, estatales y locales.

Por su parte, la ciudad de Tijuana constituye un espacio sui generis en el que se encuentran e interactúan dos sociedades, una más desarrollada (Estados Unidos), y otra menos desarrollada (México), dando como resultado una sociedad única con nuevos patrones y estilos de vida diferentes a los mexicanos y a los estadunidenses (Ojeda, 2005; Zavala-Cosió \& Ojeda, 2011).

Por lo anterior, Tijuana es considerada como un lugar singular y relevante debido a que los procesos se desarrollan bajo relaciones internacionales consolidadas con participación de interacciones globales. El factor externo es un determinante principal en su desarrollo económico, ya sea por la intervención de la IED, por el empleo transfronterizo o por las fuertes migraciones que llegan y atraviesan a la ciudad (Coubès \& González, 2011).

En la ciudad de Tijuana, la industria electrónica desempeña un rol fundamental en la Industria Maquiladora de Exportación. En 1997, este sector representó 7 por ciento del PIB estatal manufacturero y participó aproximadamente con 1,5 por ciento del PIB de la industria electrónica del país sobre el PIB manufacturero nacional (Carrillo, 2001; López, 2008).

\footnotetext{
4 Fuente: Elaboración propia con base en el Censo Económico 2009, INEGI
} 
La industria electrónica en Tijuana se caracteriza por su alta especialización en la producción de aparatos de consumo desde bienes finales y componentes, como los televisores, computadoras, equipos de audio, ensamble de tablillas, tarjetas de circuitos, arneses y cables (Carrillo, 2001; López, 2008). A nivel mundial, la electrónica es una de las industrias más dinámicas, se ha transformado en un sector altamente globalizado y estratégico, esto gracias a su constante innovación en la microelectrónica, evolución productiva y su interacción con otras industrias, que han incorporado un número importante de componentes electrónicos para modernizarse como: la automotriz, electrodomésticos y la industria del televisor (Dicken, 1998; López, 2008).

Las tasas de crecimiento que muestra la industria electrónica superan las de otras industrias como la petrolera, la automotriz y la química. El aumento del consumo de televisores, plasmas, LCDs, LEDs, teléfonos móviles, videocámaras y consolas de videojuegos se configura como los productos con mayor demanda en los últimos años a nivel mundial. El desarrollo que ha tenido la tecnología digital hace que los productos que salen al mercado sean más atractivos y por lo tanto más demandados (López, 2008).

Si bien, la industria del televisor es el segmento de la industria electrónica más favorecido en Tijuana por el comercio exterior y la firma del Tratado de Libre Comercio con América del Norte (TLCAN), durante el periodo 1994-1999, la IED de este sector acumuló más de mil millones de dólares y generó en promedio tres mil empleos. El clúster de la industria del televisor en Tijuana está conformada por ocho ensambladoras donde los productos elaborados como LCDs, LEDs o plasmas han tenido una significativa aceptación en el mercado debido a que permiten el ahorro de energía en comparación con el CRT (Tubo de Rayos Catódicos) que era usado anteriormente, además de ser ecológicas y con una mejor calidad en imagen y sonido (López, 2008).

En el año 2001, la industria del televisor comenzó a mostrar signos de desaceleración, en parte por la recesión de la economía norteamericana y por la incorporación de China como fuerte competidor en Estados Unidos. En el año 2000, China solo cu- bría 1,7 por ciento de la demanda norteamericana y México poco más de 73 por ciento, para el año 2005 China obtuvo 7 por ciento en este mercado y México perdió 17 por ciento de participación en el país vecino. La incorporación de China al mercado norteamericano significo el cierre de líneas de producción en plantas, sobre todo las dedicadas a la fabricación del CRT (Carrillo, 2001; López, 2008).

Asimismo, el crecimiento social y en menor medida el natural, hizo que la ciudad de Tijuana constituya una de las once Zonas Metropolitanas de México que cuenta con más de un millón de habitantes. Este resultado obedece al hecho de que la tasa de crecimiento de la ciudad durante el periodo 1990-2000 fue elevada con 5,5 por ciento anual (Palma \& Reding, 2011). Lo anterior ha hecho que Tijuana sea una ciudad receptora y expulsora de población, con gran envergadura económica por su localización estratégica con los Estados Unidos, pero al mismo tiempo una economía dependiente. El gran dinamismo económico y social de la ciudad coloca a este lugar como un espacio atractivo para su estudio.

Por último, la ciudad de Mérida, la dinámica económica de esta ciudad se consolidó por más de cien años en la industria henequenera, con formas de organización social, económica y espacial relativamente homogéneas. Sin embargo, con la implementación de políticas de apertura comercial y al proceso de globalización económica se generaron importantes cambios conduciendo a la ciudad a la terciarización de la economía, con jerarquías urbanas y nuevos procesos productivos de acuerdo a las demandas nacionales e internacionales.

Desde 1835, el henequén en rama ocupó el primer lugar entre las exportaciones de la entidad, era enviado principalmente a Estados Unidos para la fabricación de jarcias y cordeles, competía en calidad y precio con el hilo cáñamo de Rusia. Para 1875 el henequén en rama y las manufacturas representaban 69,6 por ciento de las exportaciones del estado, el resto estaba representado por el almidón, sobreros de paja, hamacas, piedras de moler, manteca de cerdo, carne salada, azúcar, cereales, miel de abeja, chicle y otros productos (Alvarado, Leyva \& Caro, 2010). 
De tal manera que el henequén y sus derivados fue, durante más de un siglo (1835-1990), el producto más importante considerado el eje rector de la configuración regional de la entidad, incluida la ciudad de Mérida. Esta mono-producción definió una región homogénea, relativamente estable, en 1980 el henequén representaba 72 por ciento del total de las exportaciones y captaba alrededor de 68,1 por ciento de la población de Mérida como mano de obra. No obstante, al paso de los años, la pérdida de influencia en la producción henequenera fue total, para 1986 la producción fue de sólo 7,8 por ciento. Esta situación hizo que tomaran importancia otras actividades como: la industria apícola, salinera, procesamiento de cítricos, pesca, entre otras (INEGI, 2000; Alvarado, Leyva \& Caro, 2010).

Junto con el proceso de la globalización económica que tienden a concentrar y centralizar el capital, se presentó la eliminación de los subsidios al agave controlado del henequén, se disolvieron los ejidos colectivos y se privatizó la industria henequenera. A finales de la década de los años ochenta y principios de los noventas, se impulsó la industrialización en el estado de Yucatán con la modernización de comunicaciones terrestres y ampliación de rutas marítimas. Específicamente en 1984, la ciudad de Mérida se convirtió en el punto de atracción económica y pasa a ser la sede de grandes monopolios, nacionales $e$ internacionales, ello trajo consigo fuertes corrientes migratorias. En 1992, se realiza el desplazamiento de la industria maquiladora a diferentes poblaciones de la entidad, donde comienza la concentración y recomposición del capital compitiendo con los grupos locales por el dominio del mercado regional y finalmente la aristocracia henequenera fue desplazada por los nuevos capitalistas. De manera que 40 mil ejidatarios tuvieron que buscar un empleo en la ciudad de Mérida (Alvarado, Leyva \& Caro, 2010; García \& Ruiz, 2011).

Ante la mayor apertura comercial que estaba viviendo el país, a inicios de la década de 1990, en la ciudad de Mérida se estimularon a las empresas locales para aprovechar las ventajas de Puerto Progreso, a partir de ese momento las exportaciones se realizaban a través del sector maquilador apoyado principalmente por capital extranjero. La industria maquiladora hizo uso intensivo de la mano de obra no calificada -que provenía principalmente del área rural- $y$ sus procesos productivos no se caracterizaron por incluir tecnología de punta ni los productos representaban un conocimiento innovador. Sin embargo, este sector inyectó dinamismo a la economía ofreciendo nuevas expectativas al desarrollo industrial. En especial el subsector textil y del vestido fue donde se dio una generación masiva de empleo (Alvarado, Leyva \& Caro, 2010).

El sector turístico representa la actividad terciaria más importante de la ciudad. Su historia, sus yacimientos arqueológicos, playas, cenotes, reservas naturales, ciudades coloniales, gastronomía y su clima hacen que sea un lugar paradisiaco para el turismo nacional y extranjero. Para impulsar este sector, se han recuperado las grandes haciendas henequeneras de la región convirtiéndolas en hoteles de lujo, lugares de retiro, de reflexión y meditación para los visitantes. El sector terciario incluye principalmente, al comercio, la hotelería, las finanzas, los transportes y las comunicaciones. Estas actividades representan aproximadamente 75 por ciento de la PEA ocupada total, y es el sector más equitativo en cuanto a distribución por sexos de los puestos de trabajo.

La ciudad de Mérida representa la economía local más importante del estado de Yucatán por proveer bienes y servicios a las ciudades y municipios aledaños, es un centro económico que tiene relación con otros estados como Quintana Roo, Campeche, Tabasco y Chiapas. Además en esta ciudad se encuentran la mayoría de las actividades sociales, financieras económicas, comerciales y políticas del Estado, que hace que tenga un flujo continuo de personas.

En suma, Toluca es una ciudad con vocación productiva en industrias tradicionales. Tijuana es una ciudad industrial y comercial orientada a la exportación y, Mérida una ciudad especializada en el sector servicios, en especial los turísticos. Por lo tanto, la selección de estas ciudades tiene la ventaja de que permite analizar a la precariedad en diferentes contextos: de alto dinamismo y con especialización productiva concentrada en el sector industrial y de servicios. 
Dicho lo anterior, la Tabla 3 muestra los resultados de los siete indicadores que definen al empleo precario; se observa que los jóvenes asalariados de la ciudad de Tijuana registran mejores condiciones de empleo que los jóvenes de Toluca y Mérida. Como se ha mencionado, una de las características del empleo precario es la remuneración insuficiente, para estimar los bajos ingresos de la población joven asalariada se utilizó el salario mínimo. Para el caso de Tijuana, 13,3 por ciento de los jóvenes en 2005 recibían menos de dos salarios mínimos, para el año 2010 la proporción se incrementó a 24,1 por ciento. A pesar de este incremento de diez puntos porcentuales, esta proporción de jóvenes en tal situación es la más baja de las tres ciudades, debido a que en Toluca y Mérida la proporción supera o incluso duplica a la población joven con salarios insuficientes registrada en la ciudad fronteriza.

En este orden de ideas, la población joven que recibe menos de dos salarios mínimos no puede asegurar su bienestar económico propio ni el de sus hogares. Con remuneraciones insuficientes, este grupo de población, y ningún otro, puede tener la posibilidad de mejorar su formación profesional y mucho menos incrementar su calidad de vida. Ante esta situación los jóvenes demandarían más horas de trabajo, sin embargo con jornadas de trabajo excesivas la población joven está expuesta a una gran cantidad de situaciones prejudicial afectando su salud física y mental, además impiden el equilibrio entre el empleo con la vida personal, familiar y social.
En cuanto a los empleos temporales sobresale la ciudad de Toluca al registrar cerca de siete de cada diez jóvenes en esta situación, participación que se incrementó de 2005 a 2010, mientras que en Mérida la proporción es ligeramente superior al 50 por ciento. En contraste, Tijuana registra las menores participaciones de empleo temporal. De igual manera, Toluca y Mérida registran la mayor presencia de jóvenes sin acceso a atención médica, las proporciones de población joven sin servicios médicos que registran estas dos ciudades son cercanas al doble de lo que se registra en Tijuana. La inestabilidad laboral en la que se encuentra una gran proporción de jóvenes va más allá de la pérdida de la remuneración, cambiar de empleo constantemente altera el proceso de acumulación de experiencia y, en ocasiones, los conocimientos prácticos se vuelven inservibles, se suma a lo anterior la reducción de algunas prestaciones sociales, en particular la pensión de jubilación por el rompimiento de la antigüedad en el trabajo. Asimismo, la poca presencia que tienen los jóvenes en el rubro de la atención médica los coloca en una situación de vulnerabilidad, de injusticia social $y$ de deterioro de sus beneficios laborales, debido a que al carecer de seguridad social los jóvenes asalariados quedan fuera del amparo frente a diversos imprevistos como: accidentes, enfermedades, maternidad, incapacidad o múltiples riesgos que pueden correr en el lugar de trabajo o como consecuencia de éste.

Tabla 3. Indicadores de las condiciones laborales de Toluca, Tijuana y Mérica, 2005 y $2010^{5}$

\begin{tabular}{lcccccc}
\hline \multirow{2}{*}{\multicolumn{1}{c}{ Indicador }} & \multicolumn{2}{c}{ Mérida } & \multicolumn{2}{c}{ Tijuana } & \multicolumn{2}{c}{ Toluca } \\
\cline { 2 - 7 } & 2005 & 2010 & 2005 & 2010 & 2005 & 2010 \\
\hline Salario mínimo & $57.7 \%$ & $49.0 \%$ & $13.3 \%$ & $24.1 \%$ & $45.2 \%$ & $38.5 \%$ \\
Temporalidad & $55.9 \%$ & $54.8 \%$ & $44.1 \%$ & $45.4 \%$ & $66.0 \%$ & $69.6 \%$ \\
Atención médica & $43.2 \%$ & $40.9 \%$ & $22.6 \%$ & $28.5 \%$ & $42.5 \%$ & $46.5 \%$ \\
Prestaciones sociales & $28.4 \%$ & $26.5 \%$ & $22.3 \%$ & $25.8 \%$ & $39.8 \%$ & $45.0 \%$ \\
Jornada de trabajo & $48.7 \%$ & $54.3 \%$ & $47.7 \%$ & $43.6 \%$ & $39.8 \%$ & $33.0 \%$ \\
Sindicato & $95.6 \%$ & $94.6 \%$ & $95.2 \%$ & $95.7 \%$ & $86.5 \%$ & $88.6 \%$ \\
Contrato & $50.2 \%$ & $48.6 \%$ & $25.9 \%$ & $30.1 \%$ & $42.8 \%$ & $45.5 \%$ \\
\hline
\end{tabular}

5 Fuente: Elaboración propia con base en la ENOE, primeros trimestres de 2005 y 2010. INEGI. 
La participación de jóvenes que no reciben ninguna prestación laboral como aguinaldo, vacaciones con goce de sueldo, crédito a la vivienda y otros es mayor en Toluca que en las otras dos ciudades. Los datos evidencian que esta situación de precariedad aumentó en las tres ciudades, pero el mayor incremento se registró en Toluca con cinco puntos porcentuales en el lustro de 2005-2010.

Respecto al indicador de la jornada de trabajo, los datos muestran que las ciudades de Mérida y Tijuana registraron las proporciones más altas de jóvenes con jornadas laborales inferiores a $35 \mathrm{y} / \mathrm{o}$ superiores a 48 horas semanales. Esta situación genera, por un lado, bajos ingresos para los jóvenes debido a que trabajan menos de 35 horas semanales $y$, por otro lado, jornadas excesivas superiores a 48 horas a la semana traen consigo problemas graves para la salud. La misma situación se presenta para el caso de la afiliación al sindicado, donde Mérida y Tijuana son las ciudades con los registros más altos de jóvenes sin esta prestación. Sin la afiliación a un sindicato la población joven asalariada queda excluida de defender sus intereses laborales, no entra en las negociaciones con el empleador para las condiciones de contratación y de trabajo, queda excluida del diálogo social, y con ello queda fuera de la relación entre los interlocutores sociales y las autoridades públicas. Por lo tanto, los jóvenes quedan desamparados por los acuerdos y convenios colectivos establecidos entre las organizaciones sindicales y los empleadores y, como consecuencia de ello, el deterioro generalizado de sus derechos laborales.

Paralelamente, los resultados de la situación laboral respecto al contrato de trabajo indican que uno de cada dos jóvenes de la ciudad de Mérida desempeña actividades sin contrato escrito, en Toluca la proporción de jóvenes en la misma condición es ligeramente inferior. Mientras que en Tijuana son máximo tres de cada diez jóvenes los que se encuentran sin contrato escrito y con ello una mayor proporción de jóvenes se encuentra en una mejor situación laboral. Lo anterior indica que una mayor cobertura de empleos sin contratos generaría menores beneficios para los trabajadores, menores incrementos salariales para ellos y, por lo tanto la reducción de responsabilidades por parte del empleador.
En suma, los resultados son contundentes al mostrar las mejores condiciones laborales en que se encuentran los jóvenes asalariados de la ciudad de Tijuana, en esta ciudad se registra la menor proporción de población joven con menores ingresos, con empleos temporales, sin atención médica, sin prestaciones laborales, sin contrato escrito y con jornadas de trabajo inferiores o superiores a las de la Ley del Trabajo. Por el contrario, en cuatro de los siete indicadores se muestra que los jóvenes de la ciudad de Toluca registran peores condiciones laborales en cuanto al salario mínimo, empleo temporal, atención médica y prestaciones laborales. Por su parte, la ciudad de Mérida no está exenta de ofrecer empleos precarios a la población joven, especialmente en lo relacionado con la jornada de trabajo, sin afiliación a algún sindicato y sin contrato escrito.

Dicho lo anterior, los resultados destacan la diversidad de situaciones laborales en que se pueden encontrar los jóvenes asalariados, ello como consecuencia de la reestructuración productiva y la flexibilidad laboral, procesos que han generado nuevas relaciones de trabajo que conducen a la inseguridad en el empleo, la disminución de los salarios y la desregulación de las condiciones de protección de los trabajadores, situaciones que promueven condiciones laborales precarias para la mayoría de los jóvenes asalariados. En estos términos se cumple la premisa básica de la flexibilidad laboral que consiste en eliminar o reducir el papel de las instituciones sindicales para replantear estrategias, nuevas formas de contratación y uso de la mano de obra.

De manera que la evidencia empírica ha mostrado que los jóvenes asalariados son parte indispensable de las estrategias flexibilizadoras de las empresas, como mínimo 40 por ciento de los jóvenes experimentan la flexibilidad laboral externa a través de un empleo temporal. Al menos tres de cada diez jóvenes forman parte de la flexibilidad interna al no tener una jornada de trabajo estable. Asimismo, hasta seis de cada diez jóvenes se encuentran con flexibilidad salarial, es decir, la remuneración de su empleo no es suficiente para satisfacer sus necesidades básicas, lo más preocupante aún es que esta situación de flexibilidad laboral se ha incrementado en el lustro 2005-2010. 
Por lo tanto se puede concluir que las estrategias empresariales han configurado escenarios laborales flexibles que no sólo conducen al deterioro de las condiciones laborales sino de la vida en general, ocasionando además desigualdad entre las ciudades analizadas y, con ello provocando una nueva configuración territorial, colocando a Tijuana como una ciudad con mayor poder económico que puede ofrecer mejores condiciones laborales a los jóvenes, en comparación a Toluca y Mérida que ofrecen malas condiciones de empleo.

\section{Estimación y estratificación del índice de precariedad laboral}

Por la diversidad de condiciones laborales que experimenta la población joven asalariada en las ciudades analizadas, se realizó la construcción de un índice de precariedad laboral, estimado a partir del análisis factorial de variables relacionadas con los niveles de precariedad laboral. De manera específica se utilizó el método de componentes principales para la construcción del índice, el cual se estratifico a partir de la técnica de Dalenius y Hodges (1959). Esto permitió clasificar al empleo en cuatro niveles de precariedad: bajo, medio, alto, extremo, y un nivel considerado empleo no precario, categorías que son mutuamente excluyentes.

\subsection{Datos}

Para estimar el índice de precariedad laboral de las tres ciudades seleccionadas se tomó como fuente de datos a la Encuesta Nacional de Ocupación y Empleo (ENOE), que realiza el Instituto Nacional de Geografía y Estadística (INEGI), en específico las encuestas correspondientes al primer trimestre de 2005 y primer trimestre de 2010. La selección del primer trimestre de la ENOE se debe a que este trimestre permite obtener mayor información de la población ocupada, debido a que en este periodo se aplica el cuestionario ampliado y, por lo tanto el instrumento tiene un mayor número de variables, esto permite la obtención de los datos necesarios para la estimación del índice de precariedad laboral, sobre todo de la afiliación sindical que en los otros trimestres no se recopila.

El levantamiento de la ENOE se realiza a partir de la elaboración de una muestra compleja con represen- tatividad a nivel nacional y de ciudades, en donde están incluidas Toluca, Tijuana y Mérida. La Tabla 4 presenta el tamaño de muestra de la población joven asalariada para cada ciudad, como se observa la muestra supera los 700 individuos en ambos trimestres para cada lugar, lo que garantiza que sean muestras estadísticamente significativas, con una distribución normal y con la ventaja de poder usar estadística inferencial. Cabe señalar que la reducción en el tamaño de muestra de las tres ciudades en el primer trimestre de 2010, se debe a la disminución relativa de la población joven dentro de la estructura por edad, lo cual no afecta el análisis.

Tabla 4. Tamaño de muestra de la población joven asalariada nacional. ${ }^{6}$

\begin{tabular}{lcccc}
\hline Año & Nacional & Toluca & Tijuana & Mérida \\
\hline 2005 & 41,041 & 799 & 710 & 780 \\
2010 & 40,031 & 717 & 709 & 731 \\
\hline
\end{tabular}

Para analizar el fenómeno de la precariedad laboral se parte de la idea, al igual que Mora (2010), que en su estimación se requiere de un análisis que vaya más allá de la polaridad entre lo precario y no precario, para nuestro caso se identificaron cuatro niveles de empleo precario y un quinto que es considerado como no precario. Las variables incluidas para determinar el nivel de precariedad de los jóvenes asalariados corresponden a tres dimensiones, que son la económica, la normativa y la de seguridad laboral. Todas las variables incluidas fueron recodificadas en variables dicotómicas, en el caso de la variable de salario mínimo se clasificó a la población joven en dos grupos, en el primero a todos aquellos que mencionaron tener ingresos menores a dos salarios mínimos y en el segundo a los que mencionaron tener ingresos por arriba.

Respecto a la dimensión normativa se encuentran variables de tipo de contrato, contratos temporales y duración de jornada de trabajo, en este caso también las variables están codificadas en variables dicotómicas en donde el aspecto positivo es la categoría de referencia. Las variables de seguridad laboral se encuentran en acceso a la seguridad social, si los jóvenes cuentan con prestaciones sociales y el nivel de sindicalización (Tabla 5).

6 Fuente: Elaboración propia con base en la ENOE, primeros trimestres de 2005 y 2010. INEGI. 
Tabla 5. Precariedad laboral: variables incluidas en el análisis ${ }^{7}$

\begin{tabular}{|c|c|c|}
\hline Dimensión & Indicador & Codificación \\
\hline 1. Económica & a. Salario mínimo & $\begin{array}{l}\text { "0" Cuando el salario es mayor a dos salarios mínimos. } \\
\text { "1" Cuando el salario es menor a dos salarios mínimos. }\end{array}$ \\
\hline \multirow{3}{*}{ 2. Normativa } & b. Contratos de trabajo & $\begin{array}{l}\text { "0" Con contrato escrito } \\
\text { "1" Sin contrato }\end{array}$ \\
\hline & c. Temporalidad & $\begin{array}{l}\text { "0" Con trabajo estable } \\
\text { "1" Sin trabajo estable }\end{array}$ \\
\hline & d. Duración de jornada & $\begin{array}{l}\text { "0" Con jornada de trabajo de } 35 \text { a } 48 \text { horas semanales } \\
\text { "1" Jornada mayor o menor a las } 35 \text { a } 48 \text { horas semanales }\end{array}$ \\
\hline \multirow{3}{*}{$\begin{array}{l}\text { 3. Seguridad } \\
\text { laboral }\end{array}$} & e. Acceso a la seguridad social & $\begin{array}{l}\text { "0" Con acceso } \\
\text { "1" Sin acceso }\end{array}$ \\
\hline & f. Prestaciones sociales & $\begin{array}{l}\text { "0" Con al menos una prestación } \\
\text { "1" Sin prestaciones }\end{array}$ \\
\hline & g. Nivel de sindicalización & $\begin{array}{l}\text { "0" Con afiliación a algún sindicato } \\
\text { "1" Sin afiliación a algún sindicato }\end{array}$ \\
\hline
\end{tabular}

\subsection{Método de estimación}

Para la estimación del índice de precariedad laboral se utilizó el análisis factorial con el método de componentes principales. Este método de reducción de datos permite estimar un vector que es el resultado de la combinación lineal de los siete indicadores de las dimensiones de la precariedad laboral. El Índice de Precariedad Laboral (IPL) es el resultado de la combinación lineal de los siete indicadores de precariedad laboral que denominaremos como iP los cuales van desde el indicador 1 hasta el $7^{1, .}$. $^{7}$ ' este sentido, la combinación lineal está dada por $\mathrm{iP}_{1.1}, \mathrm{iP}_{1.2} \ldots \mathrm{iP}_{1.7}$; la cual se expresa de manera matricial en la matriz 1 :

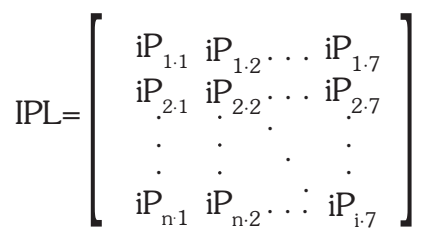

En donde:

$\mathrm{IPL}=$ matriz de indicadores de precariedad laboral.

$n=$ unidad de análisis, en este caso del individuo 1 hasta el individuo $n$.
Partiendo de la matriz de indicadores (IPL) se obtuvo la matriz de correlaciones. Las componentes principales se obtienen de las variables originales una vez que éstas se estandarizaron estadísticamente.

Con el fin de eliminar los efectos de escala entre las variables, el método de componentes principales permite estandarizar las variables mediante la desviación estándar de cada variable, a partir de ello se obtiene la matriz estandarizada Z_IPL, como se muestra en la matriz 2:

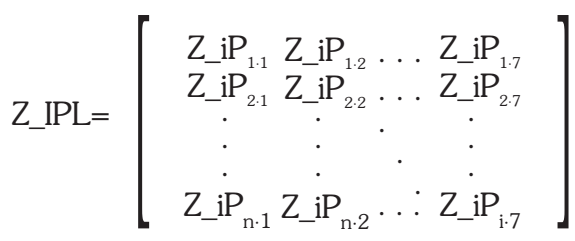

Una vez obtenida la matriz estandarizada se realiza la trasformación del espacio vectorial Z_IPL en uno nuevo. En este sentido, el método de componentes principales permite a través de la matriz de correlaciones de los siete indicadores estandarizados obtener siete vectores y siete valores propios, que están mutuamente determinados; dichos valores propios son numerados en función de su magnitud. De esta manera, se considera la importancia de cada com-

\footnotetext{
7 Fuente: Elaboración propia.
} 
ponente de acuerdo a la proporción de varianza que explica el total de los siete vectores propios.

El nuevo valor de Y1 de cada nivel de análisis representa una medida resumen de los siete indicadores originales estandarizados que resumen su efecto en un valor como se muestra en la ecuación 1 :

$$
\begin{gathered}
\mathrm{Y} 1=\mathrm{a}_{1.1} \mathrm{Z}_{-} I P L_{1}+\mathrm{a}_{1.2} \mathrm{Z}_{-} I P L_{2}+\ldots+\mathrm{a}_{1.7} \mathrm{Z}_{-} I P L_{7}= \\
\mathrm{a}^{1} . \mathrm{Z}_{-} I P L_{=} I P L
\end{gathered}
$$

Una vez obtenido el índice se realizaron los siguientes pasos:

a) Se extrajo el número óptimo de factores; bajo el criterio de raíz latente, que implica que los factores conformados justifican la varianza de por lo menos una única variable.

b) Se realizó la rotación de la solución con la finalidad de maximizar la varianza, por lo cual se utilizó el método de VARIMAX (máxima varianza), que se centra en simplificar las columnas de la matriz de factores alcanzando la máxima simplificación posible. Asimismo, este método permitió minimizar la suma de las varianzas de las cargas requeridas de la matriz de factores, siendo más robusto en comparación de otros métodos dando una separación más clara de los factores y, por último;

c) Se obtuvieron las puntuaciones factoriales de cada uno de los individuos en las nuevas dimensiones con las que se estimó el Índice de Precariedad Laboral, a partir del cual se estratificaron los niveles de empleo precario.

Los resultados del análisis de factores permitieron establecer que las asociaciones entre las variables de precariedad se agrupan en dos factores o componentes que explican a nivel nacional alrededor del 62,98 y 63,01 por ciento de la varianza para el año 2005 y 2010 , respectivamente y 61,$75 ; 62,06$ por ciento para las tres ciudades, en ese mismo orden. Una vez determinado el número de factores, los modelos factoriales fueron contrastados para los dos años a partir del estadístico de Kaiser-Meyer-Olkim (KMO), el cual señaló que los modelos propuestos tienen buen nivel de ajuste. A través de la prueba de esfericidad de Bartlett se pudo concluir formalmente la existencia de correlaciones significativas entre las variables utilizadas a un nivel de $95 \%$ de confianza. Los resultados desglosados del análisis factorial se pueden consultar en el anexo estadístico.

Para estratificar el índice de precariedad laboral se utilizó el criterio de mínima varianza de Dalenius y Hodges (1959), que consiste en hallar una estratificación óptima, definida como aquella en la cual la varianza del estimador sea mínima al interior de los grupos y al mismo tiempo la varianza del estimador sea máxima entre éstos, es decir, esta técnica permite conformar grupos homogéneos en su interior y lo más heterogéneos entre sí. La variable resultante de la estratificación obtenida, expresada en puntajes, tiene la característica de ser continua y con una distribución aproximadamente normal, lo que posibilitó a través del cálculo de algoritmos la obtención de una distribución óptima con mínima varianza inter grupos, lo cual significa que las frecuencias relativas de los puntajes de la variable de estratificación se distribuye en rangos iguales. Los rangos fueron estimados a partir de la raíz cuadrada de la frecuencia y frecuencia acumulada de cada intervalo para la distribución de niveles. Esta técnica de estratificación permitió clasificar al índice de precariedad laboral en cinco rangos, los cuales determinan cuatro niveles de empleo precario: bajo, medio, alto y extremo y, un grupo considerado empleo no precario.

La Tabla 6 muestra el límite inferior y superior en el que se encuentra cada nivel de empleo precario de la población joven asalariada, a nivel nacional y para las tres ciudades, en los dos periodos de estudio.

\subsection{Resultados}

Los cuatro niveles de empleo precario (bajo, medio, alto y extremo) muestran el deterioro progresivo de las condiciones laborales de los jóvenes asalariados. El nivel bajo de empleo precario se caracteriza porque sólo en uno de los siete indicadores los jóvenes se ven afectados, la condición laboral donde se encuentran vulnerables es en la afiliación a un sindicato. Por su parte, el nivel medio de empleo precario implica que los jóvenes además de tener poca presencia en la afiliación 
Tabla 6. Estratificación del índice de precariedad laboral a nivel nacional y para las tres ciudades 2005 y $2010 .{ }^{8}$

\begin{tabular}{|c|c|c|c|c|c|c|c|c|}
\hline \multirow{3}{*}{$\begin{array}{c}\text { Nivel de empleo } \\
\text { precario }\end{array}$} & \multicolumn{4}{|c|}{ Nacional } & \multicolumn{4}{|c|}{ Tres ciudades } \\
\hline & \multicolumn{2}{|c|}{2005} & \multicolumn{2}{|c|}{2010} & \multicolumn{2}{|c|}{2005} & \multicolumn{2}{|c|}{2010} \\
\hline & Inferior & Superior & Inferior & Superior & Inferior & Superior & Inferior & Superior \\
\hline No precario & -0.85 & -0.68 & -0.83 & -0.69 & -0.66 & -0.56 & -0.74 & -0.61 \\
\hline Bajo & -0.69 & -0.58 & -0.7 & -0.62 & -0.57 & -0.43 & -0.62 & -0.48 \\
\hline Medio & -0.55 & -0.04 & -0.55 & -0.01 & -0.42 & -0.03 & -0.41 & -0.10 \\
\hline Alto & 0.00 & 0.37 & 0.03 & 0.39 & 0.20 & 0.35 & -0.04 & 0.38 \\
\hline Extremo & 0.41 & 0.66 & 0.44 & 0.70 & 0.43 & 0.82 & 0.50 & 0.77 \\
\hline
\end{tabular}

de algún sindicato se agrega que la jornada de trabajo se encuentra fuera de la Ley del Trabajo, es decir, su jornada laboral es inferior a 35 o superior a 48 horas semanales.

Los empleos con un nivel de precariedad alto se identifican porque en tres de los siete indicadores los jóvenes tienen poca presencia, esto son: el tipo de contrato, la temporalidad de empleo y la incorporación para recibir atención médica. En los empleos con un nivel de precariedad extremo, las condiciones laborales se encuentran aun más complicadas y por lo tanto más deterioradas, se suman a los tres indicadores del nivel alto de precariedad laboral el salario mínimo y las prestaciones laborales donde se ven perjudicados los jóvenes. Es decir, en cinco de los siete indicadores la población joven se ve afectada. Por último, los jóvenes que se ubican en un empleo no precario se caracterizan porque reciben más de dos salarios mínimos, tienen prestaciones sociales, atención médica, contrato escrito, jornada laboral de 35 a 48 horas semanales, están afiliados algún sindicato y tienen estabilidad laboral con un contrato permanente.
En la Tabla 7 se muestra la proporción de jóvenes asalariados a nivel nacional y de las ciudades de Toluca, Tijuana y Mérida según el nivel de empleo precario. Al respecto, los resultados por ciudad muestran que en Toluca y Mérida el nivel extremo de precariedad laboral concentra la mayor participación de la población joven asalariada y con ello con peores condiciones laborales. La tendencia de este nivel de empleo precario en un lustro fue diferencial en las dos ciudades, en Mérida la proporción de jóvenes se redujo cuatro puntos porcentuales, mientras que en Toluca se registró un aumento de casi tres puntos. Por su parte, Tijuana es la ciudad que registra la menor proporción de jóvenes en tal condición de precariedad, en esta ciudad se ubican dos de cada diez jóvenes asalariados, proporción que se mantuvo constante de 2005 a 2010. A nivel nacional los resultados muestran que la proporción de jóvenes con nivel de precariedad extremo pasó de 30,3 a 33,4 por ciento de 2005 a 2010.

En cuanto al nivel alto de empleo precario, la evidencia muestra que en las tres ciudades este nivel registra una participación diferencial de jóvenes, estos es, mientras que en Mérida se concentraron 16,4

Tabla 7. Niveles de empleo precario de la población joven asalariada en Toluca, Tijuana y Mérida, 2005 y $2010^{9}$

\begin{tabular}{lcccccccc}
\hline \multirow{2}{*}{ Nivel } & \multicolumn{2}{c}{ Nacional } & \multicolumn{2}{c}{ Toluca } & \multicolumn{2}{c}{ Tijuana } & \multicolumn{2}{c}{ Mérida } \\
\cline { 2 - 10 } & 2005 & 2010 & 2005 & 2010 & 2005 & 2010 & 2005 & 2010 \\
\hline Extremo & $30.3 \%$ & $33.40 \%$ & $38.6 \%$ & $41.4 \%$ & $22.2 \%$ & $22.5 \%$ & $34.6 \%$ & $30.5 \%$ \\
Alto & $18.5 \%$ & $17.40 \%$ & $7.4 \%$ & $6.5 \%$ & $4.2 \%$ & $12.0 \%$ & $16.4 \%$ & $21.9 \%$ \\
Medio & $30.0 \%$ & $31.20 \%$ & $32.3 \%$ & $31.3 \%$ & $43.7 \%$ & $37.1 \%$ & $24.2 \%$ & $29.7 \%$ \\
Bajo & $17.6 \%$ & $14.80 \%$ & $15.6 \%$ & $15.6 \%$ & $27.7 \%$ & $26.2 \%$ & $23.3 \%$ & $16.0 \%$ \\
No precario & $3.6 \%$ & $3.10 \%$ & $6.1 \%$ & $5.2 \%$ & $2.3 \%$ & $2.2 \%$ & $1.5 \%$ & $1.8 \%$ \\
Total & $100.0 \%$ & $100.0 \%$ & $100.0 \%$ & $100.0 \%$ & $100.0 \%$ & $100.0 \%$ & $100.0 \%$ & $100.0 \%$ \\
\hline
\end{tabular}

\footnotetext{
S Fuente: Elaboración propia con base en la ENOE, primeros trimestres de 2005 y 2010 . INEGI

9 Fuente: Elaboración propia con base en al ENOE, primeros trmestres de 2005 y 2010. INEGI.
} 
por ciento de los jóvenes asalariados en 2005, en Tijuana se ubicaron sólo 4,2 por ciento. Estas dos ciudades registraron aumentos para el año 2010, en Mérida el incremento fue de poco menos de seis puntos porcentuales para registrar 21,9 por ciento de jóvenes, mientras que en Tijuana el aumento fue de casi ocho puntos, registrado una participación de 12,0 por ciento para el año 2010, recordar que en el nivel alto de empleo precario los jóvenes se ven afectados porque su empleo es temporal, no tienen contrato escrito y porque no reciben atención médica por parte de su empleo. Respecto a la ciudad de Toluca, la proporción de jóvenes en este nivel se mantuvo relativamente constante en alrededor del 7 por ciento, con un ligero descenso de 2005 a 2010 que no llega al punto porcentual. A nivel nacional también se registró un descenso en la participación de los jóvenes en este nivel de empleo precario al pasar de 18,5 a 17,4 por ciento de 2005 a 2010 , respectivamente.

Respecto al nivel medio de empleo precario, grado de deterioro donde los jóvenes están afectados principalmente por no estar sindicalizados y por no tener jornadas de trabajo de 35 a 48 horas semanales, los datos muestran que en las tres ciudades analizadas una gran proporción de jóvenes se encuentra en este nivel de precariedad, sin embargo sobresale la ciudad de Tijuana, donde en el año 2005 el 43,7 por ciento de su población joven se encontraba en este nivel. Esta participación se redujo para el año 2010 poco más de siete puntos porcentuales para registrar un total de 37,1 por ciento. Por el contrario, Mérida registró un aumento de más de cinco puntos en este nivel de precariedad, al pasar de 24,2 a 29,7 por ciento de 2005 a 2010. Para la ciudad de Toluca y a nivel nacional, tres de cada diez jóvenes se ubicaron en este nivel de empleo precario en el lustro analizado.

Los resultados del nivel bajo de empleo precario no son alentadores y mucho menos para Mérida, que fue la ciudad que registró una mayor reducción de jóvenes en dicha categoría. En esta ciudad la participación de población joven asalariada pasó de 23,3 a 16,0 por ciento de 2005 a 2010, respectivamente. También en Tijuana se registró una disminución de jóvenes en este nivel, casi dos puntos, sin embargo esta ciudad fue la que registró una mayor proporción de jóvenes en esta categoría, casi tres de cada diez jóvenes se ubican en este nivel de empleo precario. Por su parte en la ciudad de Toluca 15,6 por ciento de los jóvenes asalariados se encuentran en este nivel de empleo precario, es decir, se encuentran afectados principalmente por no tener representación sindical por parte de su empleo.

La evidencia estadística indica que el empleo no precario tiene, en general, poca presencia en las tres ciudades, siendo Toluca la ciudad que registra la mayor proporción de jóvenes en este nivel, sin embargo la presencia de la población joven se redujo de 2005 a 2010, al pasar de 6,1 a 5,2 por ciento, respectivamente. En las ciudades de Mérida y Tijuana la participación de jóvenes en empleos no precarios no supera 3 por ciento del total de la población joven asalariada. En este sentido, son pocos los jóvenes que registran un ingreso igual o mayor a dos salarios mínimos, con estabilidad laboral (empleo de base o planta), con acceso a instituciones de salud, con una jornada de trabajo de 35 a 48 horas a la semana, con afiliación sindical y que reciben por lo menos una prestación como aguinaldo, vacaciones con goce de sueldo, servicio de guardería, crédito para la vivienda, entre otras.

La interpretación de estos resultados conduce a las siguientes reflexiones: por un lado se muestra que la participación que tienen los jóvenes en los empleos no precarios es realmente poca; y por otro que, una gran proporción de población joven asalariada se encuentra en el nivel extremo y nivel medio de precariedad laboral. En otras palabras, una pequeña proporción de jóvenes tiene una posición laboral privilegiada y con ello se aíslan de la incertidumbre y la variabilidad que genera la demanda de trabajo y el proceso productivo, que es el caso de los jóvenes que se encuentran en los empleos no precarios. Mientras que una gran proporción de jóvenes se comporta como un factor residual de la producción, y con ello absorben la parte de inseguridad e incertidumbre tanto de la demanda de mano de obra como de la demanda de productos, este es el caso de los jóvenes que se ubican en el nivel extremo de precariedad laboral.

La conformación de grupos por nivel de precariedad permite constatar la alta heterogeneidad laboral de los jóvenes asalariados, lo cual es explicado por la segmentación del mercado de trabajo; en este 
sentido, tenemos la conformación de un mercado primario donde se ubican aquellos jóvenes con empleos no precarios y, otro secundario donde tendrían cabida aquellos jóvenes con un nivel de precariedad extremo. La evidencia muestra que existen situaciones laborales intermedias entre lo no precario y la precariedad extrema, en esta investigación se han encontrado al menos otras tres formas más de precariedad laboral donde prevalecen empleos más seguros y estables que otros, de tal manera que se cumple la existencia de una segmentación más profunda del mercado de trabajo.

Asimismo, la evidencia señala que no es posible identificar sólo dos categorías que hagan referencia a lo precario y no precario, sino al contrario la heterogeneidad laboral permite identificar otras categorías como nivel bajo, medio y alto de empleo precario, de ahí que resulta imposible pensar en un mercado homogéneo y único como lo plantean los teóricos neoclásicos.

\subsection{Pruebas de hipótesis de proporciones y los casos de estudio}

Para saber qué ciudad ha sido la más afectada por el fenómeno de precariedad laboral, se realizaron las siguientes pruebas de hipótesis de proporciones para comprobar:

i) Que la proporción de jóvenes en los niveles de empleo precario alto y extremo sea mayor para el año 2010 respecto al año 2005, y

$$
\begin{aligned}
& \text { HO: } \pi_{\text {nivel "alto y extremo" } 2005} \geq \pi_{\text {nivel "alto y extremo" } 2010} \\
& \text { H1: } \pi_{\text {nivel "alto y extremo" } 2005}<\pi_{\text {nivel "alto y extremo" } 2010}
\end{aligned}
$$

ii) Que la proporción de población joven en los niveles de empleo precario medio, bajo y no precario sea mayor en 2005 que en 2010.

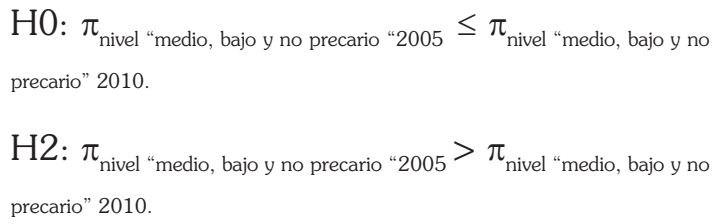

En este sentido, para responder afirmativamente a una profundización del fenómeno de precariedad laboral se tendrían que aceptar ambas hipótesis. A su vez estas hipótesis también se llevaron a cabo comprando las ciudades. Las comparaciones estadísticas y el análisis de las diferencias entre proporciones se llevaron a cabo a través del estadístico $Z$, que es aproximado por una distribución normal estandarizada, el cual permite determinar si existe evidencia estadística de una diferencia direccional, como es el caso de las hipótesis planteadas.

Vale la pena mencionar que, considerar a la proporción de jóvenes en el nivel alto y extremo se debe a que estos dos niveles son los que registran mayor deterioro de las condiciones laborales, mientras que los niveles medio, bajo y no precario son los que muestran mejores condiciones laborales. En este sentido, si la proporción de población joven en los niveles de empleo precario alto y extremo fue mayor en 2010 que en 2005, significa que una mayor cantidad de jóvenes se ubicó en condiciones laborales más precarias que un lustro antes. Por el contrario, si la proporción de jóvenes en los niveles de precariedad medio, bajo y empleo no precario disminuyó en 2010 respecto a 2005, significa que los jóvenes no lograron conseguir empleos con mejores condiciones laborales y, por lo tanto el fenómeno de precariedad se profundizo a través del tiempo.

Los resultados muestran que sólo en Tijuana existe suficiente evidencia estadística para afirmar que en el periodo de 2005-2010 el fenómeno de precariedad laboral se profundizó en esta ciudad fronteriza (ver anexo de prueba de hipótesis) ${ }^{10}$. Lo anterior llevo a plantear la siguiente pregunta ¿la ciudad de Tijuana registra la mayor proporción de población joven asalariada en peores condiciones laborales? Esta interrogante condujo a plantear dos hipótesis. La hipótesis 1 sostiene que Tijuana registra una mayor proporción de jóvenes en peores condiciones laborales, es decir en los niveles de precariedad alto y extremo en comparación con Toluca y Mérida.

10 Las pruebas de hipótesis se realizaron en PH STAT, Excel 2012. 

$\mathrm{HO}:$
$<\pi_{\text {nivel "alto y extremo" Toluca y Mérida. }}$
H1: $\pi_{\text {nivel "alto y extremo" Tijuana }} \geq \pi_{\text {nivel "alto y extremo" Toluca y Mérida. }}$

De forma complementaria, la hipótesis 2 sustenta que la ciudad de Tijuana registra una menor proporción de jóvenes en mejores condiciones laborales, es decir en los niveles de precariedad bajo, medio y en empleos no precarios, respecto a Toluca y Mérida.

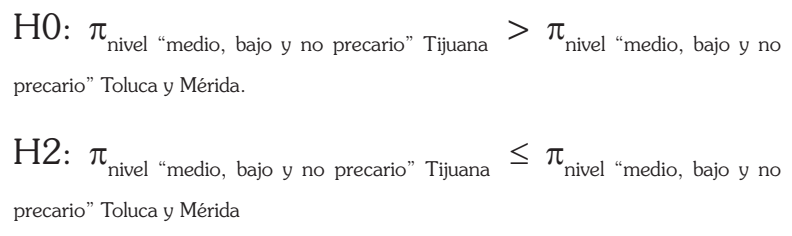

H2: $\pi_{\text {nivel "medio, bajo y no precario" Tijuana }} \leq \pi_{\text {nivel "medio, bajo y no }}$ precario" Toluca y Mérida

El análisis estadístico muestra que con un nivel de significancia de 0,05, se rechazan ambas hipótesis. De manera que no existe suficiente evidencia estadística para afirmar que la ciudad de Tijuana registra una mayor proporción de población joven asalariada en peores condiciones laborales respecto a las ciudades de Toluca y Mérida. No obstante, al realizar las pruebas de hipótesis contrastando la ciudad de Tijuana con cada una de las ciudades de manera individual y para cada nivel de empleo precario los resultados indican, con un nivel de significancia de 0,05 , que existe suficiente evidencia estadística para afirmar que la ciudad de Toluca registra una mayor proporción de jóvenes asalariados con peores condiciones laborales que en Mérida y Tijuana (ver anexo de prueba de hipótesis). Por lo tanto, se puede concluir que la ciudad de Toluca es el lugar que registra la mayor proporción de jóvenes en peores condiciones laborales, mientras que Tijuana es la registra una mayor proporción de jóvenes con mejores empleos, aunque de 2005 a 2010 se redujo su participación, lo cual influyó para que el fenómeno de precariedad laboral se haya profundizado en esta ciudad. Estos resultados del mayor deterioro de las condiciones laborales de jóvenes asalariados en la ciudad de Toluca y, la mejor situación laboral de jóvenes de Tijuana tienen su explicación en la estructura económica de cada ciudad.

La ciudad de Tijuana ofrece mejores empleos por ser un espacio fronterizo de tradición maquiladora que tiene relaciones económicas consolidadas con el exterior, principalmente, con Estados Unidos. A partir de sus relaciones globales, que se intensificaron en 1983, con los primeros centros y cadenas globales de producción orientados, especialmente a la electrónica, Tijuana ha mantenido un crecimiento en esta industria provocando una aglomeración de empresas que han logrado constituirse como un clúster de la electrónica a través de firmas trasnacionales, principalmente asiáticas, que dirigen la cadena productiva.

Esta estructura económica basada en empresas grandes dedicadas a la industria de la electrónica, sector que se considera de los más dinámicos, globalizados y especializados, ha traído consigo el ofrecimiento de mejores condiciones laborales para los jóvenes asalariados. No obstante, a pesar del crecimiento que ha registrado la electrónica y especialmente la industria del televisor en todo el mundo, la ciudad de Tijuana registró una desaceleración en su economía en el año 2010 a consecuencia de la crisis del 2009, que afectó a todos los países del mundo, pero principalmente a Estados Unidos, reflejando así un deterioro de las condiciones laborales, lo que propicio que una cantidad importante de jóvenes perdieran sus derechos laborales al cerrarse o trasladarse las plantas de producción y, con ello se profundizó el empleo precario de los jóvenes.

La profundización del fenómeno de precariedad laboral de 2005 a 2010 en la ciudad de Tijuana se debe al menos a cinco aspectos: i) la tendencia creciente de la población que recibe salarios insuficientes, indicando con ello un mayor grado de vulnerabilidad económica por parte de los jóvenes; ii) el aumento del empleo temporal y con ello una reducción proporcional del salario mensual así como la pérdida de sus beneficios y derechos laborales; iii) la acentuación de empleos sin atención médica; iv) expansión de empleos sin prestaciones laborales, v) la creciente ausencia de contratos laborales y a partir de esto el deslinde de los compromisos salariales, de protección social, antigüedad y seguridad social.

Cabe resultar que a pesar de estos cinco aspectos, el empleo que obtienen los jóvenes asalariados en esta ciudad son mejores que los empleos que se ofrecen en Toluca y Mérida. 
Por su parte, la ciudad de Toluca que si bien se caracteriza por tener un sector industrial relativamente fuerte, especialmente, en la industria automotriz, de alimentos, de bebidas y tabaco así como la industria química, estos sectores económicos son importantes pero menos dinámicos que la industria electrónica que se registra en Tijuana. Este elemento junto con una estructura económica donde no prevalecen los clusters industriales especializados, sino por el contrario en esta ciudad prevalecen los micro y pequeños establecimientos hacen que una mayor cantidad de jóvenes se encuentre en empleos con malas condiciones laborales, aunque no por ello dejan de existir los buenos puestos de trabajo. En comparación con Tijuana, la ciudad de Toluca no registra evidencia de que el fenómeno de precariedad laboral se haya profundizado, sino más bien los empleos con malas condiciones laborales existen desde el año 2005 y continúan en 2010.

Es de llamar la atención el caso de Mérida, debido a que esta ciudad se caracteriza por tener una estructura económica más heterogénea que las dos ciudades anteriores, donde el sector terciario, en especial el turístico, tiene una representación importante. De modo que las mejores condiciones laborales que ofrece esta ciudad a los jóvenes se podrían sustentar, en parte, por el crecimiento de la industria maquiladora y, por otro lado, en la importancia económica que representa el turismo. Aunque se ha evidenciado en otros estudios que en el sector terciario es donde prevalecen las condiciones laborales más precarias, los datos de esta investigación no aportan evidencias para sostener este argumento, debido a que Mérida si bien tiene un sector terciario mucho más importante que Toluca, en Mérida se ofrecen mejores condiciones laborales a los jóvenes que en la ciudad de Toluca.

Por lo tanto, la explicación diferencial de mejores o peores condiciones laborales se podría centrar en la heterogeneidad de la estructura económica que tiene cada ciudad, así como el peso relativo que tiene la industria maquiladora, la consolidación o debilitamiento de las organizaciones sindicales, el tamaño de los establecimientos $y$, en general, al dinamismo económico que predomina en cada ciudad. Sin embargo, con la globalización económica y la libre circulación del capital se han aprovechado estas tres ciudades para la reducción de costos laborales precarizando las condiciones laborales.

De tal manera que, en el nuevo escenario laboral marcado por la globalización económica, estos resultados son poco gratos debido a la mayor proporción de jóvenes que se encuentran en empleos precarios, donde no sólo se ha evidenciado una creciente polarización de buenos y malos empleos sino una variedad de situaciones de empleo en términos de calidad.

En suma, el fenómeno de precariedad laboral se evidencia en las tres ciudades, aunque con ciertas diferencias, dependiendo del dinamismo económico, del nivel de competitividad o de la especialización productiva de cada ciudad. Los resultados muestran que el empleo precario se profundizó en la ciudad de Tijuana, pero es Toluca la ciudad que registra mayor proporción de jóvenes en el nivel extremo de precariedad laboral y con ello con peores condiciones laborales. Si bien, en el lustro 2005-2010 este fenómeno afectó sobre todo a los jóvenes asalariados de la ciudad de Tijuana, los jóvenes de este lugar continúan registrando mayor presencia en mejores empleos en comparación con la participación que tienen los jóvenes en las otras dos ciudades analizadas.

\section{Conclusiones}

En los resultados obtenidos adquieren importancia, por lo menos, cuatro aspectos analíticos. El primero, el concepto de empleo precario hace referencia a las condiciones laborales bajo las cuales se insertan los jóvenes y no a sus características individuales. Segundo, se descartan sólo dos situaciones laborales: precarias y no precarias, por el contrario se presenta una diversidad de posiciones que desencadenan en magnitudes diferenciales de grados de precariedad laboral. Tercero, el cruce de los siete indicadores analizados en este estudio genera una gran diversidad de situaciones laborales precarias, esto es, los jóvenes asalariados se insertan de manera diferenciada en los sistemas de relaciones de trabajo en las empresas. Estas organizaciones los aceptan bajo diferentes modelos de contratación: empleo temporal o sin contrato, que se extienden a 
modelos de subcontratación o externalización: con jornadas cortas o excesivas, cuyo fin es la reducción de costos laborales a partir de empleos: con bajos salarios, sin prestaciones laborales, sin seguridad social y sin afiliación al sindicato.

Cuarto aspecto, el fenómeno de precariedad es de carácter multidimensional, tal como lo afirman De Oliveira (2006) y Mora (2010), es decir, que el empleo precario va más allá de solo los bajos ingresos, dimensión económica, sino que el empleo precario también está afectado por los diferentes tipos de contratos, la duración de éstos y diferenciales jornadas de trabajo, dimensión normativa, se suma esta situación de precariedad la reducción de los derechos laborales como cancelación de prestaciones, seguridad social y desindicalización, que hacen referencia a la dimensión de seguridad laboral. Por lo tanto, la definición conceptual de empleo precario propuesta en este artículo converge con la evidencia estadística, debido a que los derechos laborales básicos, captados a través de los siete indicadores, se ven afectados aún al pertenecer en el sector formal de la economía.

Asimismo, los resultados de esta investigación se suman a las evidencias de otros estudios (Weller, 2000; Palacio \& Álvarez, 2004; Mora, 2006; Mora, 2010) que muestran que los efectos positivos que se esperaban a partir de la globalización económica y la flexibilización laboral tales como: un nuevo tipo de crecimiento económico, ventajas competitivas, dinámica en los mercados laborales, mejoramiento en la calidad de los empleos, reducción del desempleo, mejor distribución del ingreso y otros aspectos no se han presentado en la mayoría de los espacios geográficos. Por el contrario, la evidencia de este análisis reafirma lo planteado por otros autores (Weller, 2000; Palacio \& Álvarez, 2004; Mora, 2010; Neffa, 2010) sobre los efectos negativos que han generado tanto la globalización económica como la flexibilización laboral del mercado de trabajo, entre los que destacan: la desigualdad $e$ incertidumbre en los ingresos, debilitamiento de carreras profesionales, inestabilidad laboral, situaciones más frecuentes de marginalidad, pero sobre todo el aumento de la precariedad laboral.
Al respecto autores como Carnoy (2001), Mora (2006), Castillo (2009), Mora \& De Oliveira (2009), Mora (2010) y otros sostienen la hipótesis de que la globalización y la reestructuración económica junto con la flexibilidad laboral han generado el deterioro en las condiciones laborales, situación que conduce a la expansión del empleo precario en diferentes espacios territoriales, tanto en economías desarrolladas como en las emergentes. Los resultados de este artículo muestran que los diferentes tipos de flexibilidad laboral que se han llevado a cabo en las tres ciudades, han tenido como resultado final empleos precarios para los jovenes con diferente grado de deterioro en sus condiciones laborales. Esto indica que las estrategias flexibilizadoras adoptadas por los empresarios a partir de la globalización económica han favorecido a la expansión del empleo precario en las tres ciudades seleccionadas, debido a las nuevas formas de contratación de la mano de obra, las cuales han conducido al deterioro de las condiciones de empleo de los jóvenes asalariados; pero también por el debilitamiento y la poca presencia que tienen las instituciones y los sindicatos en las tres ciudades de interés. Por lo tanto, las prácticas de flexibilidad laboral captadas por estos siete indicadores han generado mayor precariedad laboral lo que equivale a más empleos precarios. De tal manera que con la expansión del empleo precario se calificaría como negativo el efecto de la reestructuración económica y la flexibilidad laboral en Toluca, Tijuana y Mérida.

Asimismo, destacar que los resultados finales de los diferentes niveles de empleo precario se presentan dentro del sector formal que alude al segmento más estructurado de la economía, donde se cree que los empleos son mejores o por lo menos aun existe una relación laboral fordista. Ante esto, podemos coincidir con la OIT $(2010,2012)$ cuando afirma que el empleo asalariado no es sinónimo de "trabajo decente" lo que en este artículo sería "empleo no precario", es decir, con puestos de trabajo donde los empleados no puedan correr graves riesgos económicos a pesar de ser asalariados (OIT, 2010, 2012). Los resultados referentes a este sector traen a colación lo que Neffa (2010) plantea y cuestiona sobre la posibilidad de la desaparición de la línea divisoria entre el sector informal y el sector formal. 
La existencia de investigaciones como las de Castillo $(2001,2009)$ muestran que el empleo precario está presente en las actividades más formales al igual que en las actividades informales. En el mismo sentido, Waisgrais (2001) sostiene que la alta correlación que existe entre la precariedad laboral (sector formal) e informalidad (sector informal), puede entenderse como un deterioro generalizado en la calidad laboral. Nuestra opinión al respecto es que, el sector informal y el sector formal tienen características que los hacen únicos, diferenciables y complementarios entre sí, pero que en ambos pueden existir situaciones de precariedad, aunque no necesariamente del mismo grado o nivel, la mayor presencia de la precariedad laboral dentro del sector formal es una similitud con el sector informal, pero no conduce a la desaparición absoluta de las diferencias entre ambos sectores, esto nos llevan a apoyar el planteamiento que la informalidad y la precariedad no son situaciones idénticas, aunque se pueden presentar de manera conjunta pero también de forma aislada, estos argumentos nos conducen a tres conclusiones: la primera, la complejidad del funcionamiento de los mercados de trabajo, la segunda la existencia de diferentes segmentos laborales $y$, tercera, es un hecho evidenciable que la precariedad laboral y la expansión del empleo precario se han convertido en elementos fundamentales para analizar y entender el funcionamiento actual de los mercados de trabajo, sean informales o formales.

Bajo este contexto, el empleo precario no es una actividad ilegal, ni clandestina y mucho menos fraudulenta, más bien el empleo precario constituye una práctica común en el sector formal de la economía que se apoya de los medios legales, lo cual ha sido formalizado de manera reciente en la reforma laboral aprobada en México en 2012, en la cual se privilegia una mayor flexibilidad numérica, y se fomenta de manera directa los contratos de prueba, de capacitación, y la contratación temporal. Al quedar relegada la contratación de largo plazo, es un elemento que puede intensificar el nivel de precariedad no solo de los jóvenes, sino de manera generalizada a la población ocupada.

A colación de la importancia que tiene la reforma laboral en la explicación del deterioro de las condiciones laborales, los resultados encontrados en este estudio dan pauta a afirmar que sin ayuda de las reformas laborales, a favor de la flexibilidad laboral, se han presentado de facto los cambios en la forma de contratación, duraciones en la jornada de trabajo, el debilitamiento de los sindicatos, y otros aspectos que se han presentado para la reducción de los costos laborales y crear empleos sin prestaciones ni seguridad social. Por lo tanto este artículo agrega evidencias para sostener la existencia de la flexibilidad laboral en México desde hace tiempo, que legalmente aun no estaba autorizada, pero que en la práctica se presenta ya con múltiples modalidades, en otras palabras se encontró que una parte importante de los trabajadores ya tenían condiciones laborales flexibles en lo funcional, salarial y numérico antes de que la reforma laboral se llevará a cabo.

Estos hallazgos nos conducen a la siguiente reflexión: que no se ha logrado la aplicación plena ni de la Constitución Mexicana ni de la Ley de Trabajo, en el sentido del incumplimiento del Artículo 123 constitucional, el cual no logra un estado mínimo de bienestar para todos los trabajadores del país al no tener un trabajo digno y socialmente útil. Por su parte, la legislación laboral o Ley del trabajo entendida como la normatividad de las relaciones de trabajo, en su concepto original de acuerdo a De la Garza (2011), no se originó para reforzar las relaciones de mercado sino fue concebida para plantear los derechos y obligaciones frente a la desigualdad que el mercado generaba. En este sentido, desde nuestro punto de vista existe una distorsión en el planteamiento de las reformas laborales que provienen principalmente por las presiones de las organizaciones empresariales que conducen, en general, hacia la flexibilidad del trabajo, pero en tal proceso solo se está tomando en cuenta a una parte de los dos segmentos involucrados que son los empresarios, quienes han promovido una reforma laboral a fin a sus intereses, mientras que el sector obrero ha sido ignorado.

En este sentido, el aspecto central de la reforma laboral en México consiste en la flexibilidad del trabajo a través de: i) contratos a prueba; ii) contratos de capacitación; iii) contratos por tiempo indeterminado discontinuos; iv) la polivalencia; v) jornada semanal flexible; vi) días de descanso flexibles; vii) facilidades para el despido; viii) comisión de ca- 
pacitación y productividad; ix) salario por bonos de productividad (De la Garza, 2011).

Estos aspectos, de forma individual o en conjunto, repercuten negativamente en las condiciones laborales de los trabajadores, ya sea en las prestaciones, en la jubilación o en bajos salarios, asimismo modifican la estabilidad y permanencia en el empleo; facilitan y abaratar los despidos.

De manera específica, las primeras tres propuestas se refieren a la flexibilidad numérica, impactan la estabilidad en el puesto de trabajo; las cuatro restantes a la funcional (uso de la mano de obra dentro del proceso productivo) (De la Garza, 2000), y la última en el ámbito salarial, colocar el salario en función de productividad y calidad o desempeño conduce a los trabajadores a una situación de la vulnerabilidad y pobreza.

Por lo tanto compartimos la postura de aquellos autores como De la Garza (2000), Mercado (2010) y otros que sostienen que la reforma laboral formalizaría, por un lado, a la precarización del trabajo, las bajas remuneraciones y el deterioro del sus derechos laborales y, por otro la reforma garantizaría a los empresarios la agilización del despido, la reducción de sus responsabilidades y en general a la mayor acumulación de capital. Con ello, se institucionalizan o legalizan las prácticas flexibles utilizadas en el sector formal de la economía, conduciendo a un mercado laboral más flexible de lo que ya es. En otras palabras, con un mercado laboral más flexible y nuevas formas de contratación de mano de obra, se expanden los empleos temporales, los contratos de tiempo parcial y los bajos salarios, esto conduciría al deterioro generalizado de las condiciones laborales. De ahí, que desde nuestro punto de vista, la reforma laboral no estimularía el aumento del empleo de calidad, sino más bien profundizaría la desigualdad social, laboral y económica. Bajo este panorama, Mercado (2010) denomina a la reforma laboral como una contrarreforma laboral, y equivocado no está, en el sentido de que deroga las conquistas históricas de la clase trabajadora mexicana, mientras que facilita a los empresarios la apropiación del trabajo impago y, con ello, el incremento de su capital.
Respecto a las ciudades seleccionadas se puede agregar que en este lustro analizado se observa un fenómeno de precariedad laboral más extendido sobre todo para la ciudad de Tijuana, y con ello una mayor vulnerabilidad de los jóvenes ante el avance del empleo precario. Si bien, las tres ciudades seleccionadas muestran mercados de trabajo segmentados con realidades donde prevalece una diversidad de situaciones laborales y productivas, situación que ha caracterizado históricamente al mercado de trabajo mexicano, también es cierto que se encuentran diferencias al interior de estas ciudades, Tijuana con mejores condiciones laborales y Toluca que ofrece peores condiciones de empleo.

Estos resultados cuestionan a quienes planteaban argumentos acerca de mercados laborales más igualitarios, con mayor auge a aquellos lugares más alejados y desprotegidos, por el contrario la globalización económica como afirma Castillo (2009) ha modificado y sobre todo, nosotros agregarías, acentuado las estructuras funcionales de las ciudades, creando situaciones contradictorias entre las tendencias de homogeneización, uniformización y desigualdades sociales.

Estas evidencias aportan elementos para apoyar la idea de que el crecimiento económico no ha sido suficiente para crear mejores empleos, sino por el contrario el crecimiento de la economía bajo este nuevo modelo es tan deficiente que la calidad de los empleos ha empeorado en la tres ciudades de estudio, sobre todo en la caso de Tijuana, donde la economía de esta ciudad depende fuertemente de las relaciones que tiene con Estados Unidos y por lo tanto del desempeño de su economía, al respecto valdría la pena pensar en una estrategia para impulsar a la economía local de la ciudad, preocuparse en impulsar el desarrollo de industrias y servicios a partir de la inversión de capital nacional y con ello fomentar el mercado local.

Asimismo, se puede sostener que los resultados coinciden con los planteamientos teóricos de la segmentación de mercados. En este sentido, fue posible identificar diferentes segmentos, algunos con empleos con buenas o mejores condiciones laborales, otros con empleos que obtienen menos benefi- 
cios y otros segmentos que ofrecen empleos con un nivel extremo de precariedad.

De tal modo que la heterogeneidad laboral en que se encuentran los jóvenes asalariados permite identificar a los dos mercados de trabajo, uno primario donde se ubican aquellos jóvenes con el menor nivel de empleo precario y, otro secundario donde tendrían cabida aquellos jóvenes con un nivel de precariedad extremo. Pero entre ambos mercados, la existencia de situaciones laborales intermedias donde prevalecen unos empleos más seguros y estables que otros, y con ello esta investigación aporta elementos sobre la existencia de la segmentación dentro de la segmentación.

En concreto, los elementos teóricos de la segmentación de mercados junto con el análisis estadístico aportan información suficiente para sostener que el fenómeno de precariedad laboral se profundizó en las tres ciudades de manera conjunta, de 2005 a 2010, aunque el comportamiento de este fenómeno se presentó de manera diferencial al interior de las tres ciudades. Al respecto, el análisis por ciudad muestra que en la ciudad de Tijuana se agravó el fenómeno de precariedad laboral lo que implica la expansión del empleo precario entre los jóvenes en el lustro analizado, aunque es la ciudad de Toluca el lugar que registra la mayor proporción de jóvenes en peores condiciones laborales.

En suma, el fenómeno de precariedad laboral se evidencia en las tres ciudades, aunque con ciertas diferencias, dependiendo del dinamismo económico, del nivel de competitividad o de la especialización productiva de cada ciudad. La evidencia empírica muestra que los jóvenes asalariados de las tres ciudades son parte indispensable de las estrategias flexibilizadoras de las empresas. Estos mecanismos han configurado escenarios laborales flexibles que no sólo conducen al deterioro de las condiciones laborales sino de la vida en general, ocasionando además desigualdad entre las ciudades analizadas y, con ello provocando una nueva configuración territorial, colocando a Tijuana como una ciudad con mayor poder económico que puede ofrecer mejores condiciones laborales a los jóvenes pero que a su vez ha sido la más afectada por los cambios económicos globales.
Finalmente agregar que esta investigación no pretende dar una mirada única y definitiva sobre los niveles de empleo precario en México, sino abrir un espacio de discusión para conocer las condiciones laborales bajo las cuales se encuentran los jóvenes asalariados, de tal modo que aún existen muchas interrogantes por contestar como: ¿Qué factores influyen para que la población joven asalariada se ubique en un determinado nivel de precariedad?, ¿Cuál de éstos factores es el más importante? Preguntas que se intentarán contestar en futuros artículos.

\section{Referencias}

Alvarado, S. Leyva, C. \& Caro, M. (2010). "Situación actual del mercado de los principales rubros de exportación del estado de Yucatán". En: Revista de Economía, Universidad Autónoma de Yucatán, XXVII (74), Mérida, Yucatán: 63-84.

Aranda, J. (2005). "Tercerización y precarización del trabajo en la Zona Metropolita de Toluca, 1980-2000”. En: Papeles de Población, Universidad Autónoma del Estado de México, № 046, Toluca, México: 109-137.

Caire, G. (1982). "Precarisation des emplois et regulation du marche du travail". En: Sociologie du Travail, № 2.

Camarena, R. (2004). "Los jóvenes y el trabajo". En: Navarrete, E. (coord.). Los jóvenes ante el siglo XXI, El Colegio Mexiquense, Primera edición, Toluca, México: 95-133.

Carnoy, M. (2001). El trabajo flexible en la era de la información, Alianza Editorial, Madrid, España, Traducción Jesús Albores Rey.

Carrillo, J. (2001). Inversión Extranjera Directa y eslabonamientos locales: experiencias y el rol de las políticas el caso de la industria mexicana de la televisión en Tijuana, Memoria de LASAK 2001 Internacional Conferencie Globalization and Foreign Investmen: Mexican Maquiladora and Asian Investmen, Séul.

Carty, L. (1999). El debate sobre la calidad del empleo: el caso de los Estados Unidos de América, 1970-1990. En: Castillo, D. (2009). Los nuevos trabajadores precarios. Miguel Ángel Porrúa. México, D.F.

Castel, R. (1994). "Problematization as a Mode of Reading History", Jan Goldstein (coord.). Foucault and the wrinting of History, Blackwell, Oxford, Gran Bretaña y Cambridge, Estados Unidos.

Castel, R. (1995). La metamorfosis de la cuestión social. Gallimard, París.

Castel, R. (1998). "La nueva cuestión social", La metamorfosis de la cuestión social. Una crónica del salariado, Paidós, Buenos Aires.

Castel, R. (2003). La inseguridad social ¿qué es estar protegido? Manantial, Buenos Aires.

Castillo, D. (2001). "Los nuevos precarios, ¿mujeres u hombres? Tendencias en el mercado de trabajo urbano en Panamá, 19821999". En: Papeles de población, Universidad Autónoma del Estado de México, №. 27, Toluca, México: 99-145.

Castillo, D. (2009). Los nuevos trabajadores precarios. Miguel Ángel Porrúa. México, D.F.

Censo Económico (2009). INEGI. Aguascalientes, México.

Córdova, E. (1985). "Nuevas formas y aspectos de las relaciones de trabajo atípicas". XI Congreso Internacional de Derecho del Trabajo y la Seguridad Social, Caracas, Venezuela. 
Coubès, M. \& González, R. (2011). Experiencias de vida de los jóvenes en Tijuana: Las interrelaciones entre escuela y trabajo. En: Ojeda, N. \& Zavala-Cosío, E. (coord.). Jóvenes fronterizos/ Border Youth. Expectativas de vida familiar, educación y trabajo hacia la adultez, Primera edición, El Colegio de la Frontera Norte, Tijuana, México: 57-78.

Dalenius, T. \& Hodges, J. (1959). "Minimum Variance Stratification". En: Journal of the American Statistical Association, No. 54: 88-101.

De la Garza, E. (2000). "Fin del trabajo o trabajo sin fin". En: De la Garza, E. (coord.). Tratado Latinoamericano de sociología del trabajo, El Colegio de México, México, D.F.: 755-778.

De la Garza, E. (2011). Reflexiones acerca de la Reforma Laboral. Universidad Autónoma Metropolitana. Disponible en http://docencia.izt.uam.mx/egt/publicaciones/articulos/reflexiones.pdf

De Oliveira, O. (2006). "Jóvenes y precariedad laboral en México". En: Papeles de Población, Universidad Autónoma del Estado de México, 12 (49), Toluca, México: 37-73.

De Soto, H. (1987). El otro sendero, la revolución informal. Editorial La Oveja Negra, Bogotá.

Dicken, P. (1998). Global Shift. Transforming the World Economy. Paul Chapman Publishig, London.

ENOE. INEGI [en línea]: Disponible en: <http://www.inegi.org. $\mathrm{mx}>$ [Consulta: en 23-25 de marzo de 2010 y $15-19$ de junio de 2010].

Ferreira, M. (2006). La precarización del trabajo en la ciudad como una de las nuevas formas de empobrecimiento en Colombia, Universidad Industrial de Santander, Bucaramanga.

García, B. (2001). "Reestructuración económica y feminización del mercado de trabajo en México". En: Papeles de Población, Universidad Autónoma del Estado de México, 7 (27), Toluca, México: 45-61.

García, B. (2006). "La situación laboral precaria: marcos conceptuales y ejes analíticos pertinentes". En: Trabajo, 2 (3), México, D.F.: 23-52.

García, B. \& De Oliveira, O. (2001a). "Transformaciones recientes en los mercados de trabajo metropolitanos de México". En: Estudios Sociológicos, XIX (57): 653-689.

García, B. \& De Oliveira, O. (2001b). "Heterogeneidad laboral y calidad de los empleos en las principales áreas urbanas de México". En: Revista Latinoamericana de Estudios del Trabajo, 7 (14), ALAST: 145-164

García, C. \& Ruíz, O. (2011). "La segregación territorial y el rezago en el sur de la ciudad de Mérida, como resultado del crecimiento urbano descontrolado". En: Quivera, Universidad Autónoma del Estado de México, 13 (1), Toluca, México: 122-138.

Guerra, P. (1994). "La precarización del empleo: algunas conclusiones y un intento de operacionalización". En: El empleo precario y el empleo atípico: revisión bibliográfica y propuestas para el debate, PET (Documento de trabajo, 105). Santiago de Chile.

Gutiérrez, E. (1999). "Nuevos escenarios en el mercado de trabajo en México, 1983-1998". En: Papeles de Población, Universidad Autónoma del Estado de México, №. 21, Toluca, México: 21-55.

INEGI (2000). XII Censo General de Población y Vivienda, 2000, Aguascalientes México.

López, R. (2008). Escalamiento industrial y situación laboral en la industria electrónica de Tijuana a partir del TLCAN, Tesis de Maestría en Desarrollo Regionales, El Colegio de la Frontera
Norte, Tijuana, B.C. México.

Marshall, A. (1992). Circumventing Labour Protection: Nonstandard Employment in Argentina and Peru, International Institute for Labour Studies, Ginebra: 1-13.

Martínez, V. (2008). La periferia y la transición de lo rural a urbano en la Zona Metropolitana de Toluca, estado de México (1990-2005). Tesis de Maestría en Población y Desarrollo, Facultad Latinoamericana de Ciencias Sociales, México, D.F.

Mercado, H. (2010). Algunos aspectos de la reforma laboral en México. Instituto de Investigaciones Jurídicas. Disponible en: http://biblio.juridicas.unam.mx/libros/5/2458/39.pdf

Mora, M. (2006). Ajuste estructural y empleo precario: el caso de Costa Rica. Tesis de doctorado en Ciencias Sociales, Centro de Estudios Sociológicos, El Colegio de México, México, D. F.

Mora, M. (2010). Ajuste y empleo. La precarización del trabajo asalariado en la era de la globalización, Centro de Estudios Sociológicos, El Colegio de México, México, D.F.

Mora, M. \& De Oliveira, O. (2009). "El desafío de la inclusión frente a las tendencias de exclusión laboral: El empleo precario en dos países latinoamericanos". En: Revista Sociología del Trabajo, №. 66.

Morales, J. \& Villarino M., (2007). "Moda y maquila: El trabajo precarizado en la globalización". En: Revista Sociología del trabajo, №. 59: 7-34.

Navarrete, E. (2000). "La juventud en el Estado de México. Una visión sociodemográfica a partir de la Encuesta Nacional de Empleo de 1998". En: Documentos de investigación, №. 42. El Colegio Mexiquense, Zinacantepec, Estado de México.

Navarrete, E. (2001). Juventud y trabajo: un reto para principios de siglo. El Colegio Mexiquense, Zinacantepec, México.

Navarrete, E. (2002). Recesión económica y participación económica juvenil. SEMINARIOS. El Colegio Mexiquense, Zinacantepec, Estado de México.

Neffa, J. (2010). "La crisis de la relación salarial: naturaleza y significado de la informalidad, los trabajos/empleos precarios y los no registrados". En: Neffa, J. (coord.). Empleo, desempleo y políticas de empleo, Núm. 1, Primer trimestre. CEIL PIETTE, CONICET.

Noriega, F. (2009). "El trabajo en las teorías neoclásica, Teoría General de Keynes; y de inexistencia del mercado de trabajo". En: Sánchez, J. (comp.). Economía teórica y aplicada: México y el mundo, UAM. México, D.F.

Offe, C. (1992). La sociedad del trabajo: problemas estructurales y perspectivas de futuro. Alianza editorial, Madrid.

OIT (2002). El trabajo decente y el trabajo informal en los países del istmo centroamericano. Ginebra, Suiza.

OIT (2003). "Directrices sobre una definición estadística del empleo informal", adoptadas por la Decimoséptima Conferencia Internacional de Estudios del Trabajo.

OIT (2004). Tendencias mundiales del empleo juvenil. Primera edición, Ginebra, Suiza.

OIT (2005). El empleo de los jóvenes: vías para acceder a un trabajo decente. En: Conferencia Internacional del Trabajo, 93a reunión, Informe VI, Ginebra, Suiza: 3-34.

OIT (2010). Tendencias mundiales del empleo. Primera edición, Ginebra, Suiza.

OIT (2012). Tendencias mundiales del empleo 2012. Prevenir una crisis mayor del empleo, Primera edición, Ginebra, Suiza.

Ojeda, N. (2005). "Familias transfronterizas y familias transnacio- 
nales: algunas reflexiones". En: Migraciones internacionales, 3 (2), Colegio de la Frontera Norte, Tijuana, México: 167-174.

Palacio, J. \& Álvarez, C. (2004). El mercado de trabajo: análisis y políticas, Ediciones Akal, Madrid, España.

Palma, Y. \& Reding, A. (2011). "Características del inicio de la vida sexual y reproductiva de las jóvenes de Tijuana". En: Ojeda y Zavala-Cosío, M.E. (2011). Jóvenes fronterizos/Border youth: Expectativas de vida familiar, educación y trabajo hacia la adultez, Colegio de la Frontera Norte, México.

Rendón, T. \& Salas, C. (1992). Informes del proyecto: El sector informal urbano y sus necesidades de capacitación. Secretaría de Trabajo y Previsión Social, México. D.F.

Rifkin, J. \& Heilbroner, R. L. (1996). El fin del trabajo nuevas tecnologías contra puestos de trabajo, el nacimiento de una nueva era. Barcelona, España. Paidós.

Rodgers, G. (1989). "Precarious work in Western Europe: The state of the debate".

Rodríguez, M. (1994). "Características del comportamiento de la PEA realmente ocupada en la región Toluca (1950-1990)". En: Papeles de Población, Universidad Autónoma del Estado de México, №. 2, Toluca, México: 15-26.

Rojas, G. \& Salas, C. (2007). "La precarización del empleo en México, 1995-2004”. En: Revista Latinoamericana de Estudios del Trabajo, México, D.F.: 39-78.

Rubery, J. (1989). "Precarious Forms of Work in the United Kingdom".
Sotelo, A. (1997). "Globalización del capital e inversión del ciclo económico en América Latina". En: Revista Investigación Económica 219, Facultad de Economía UNAM, México: 71-84.

Sotelo, A. (1998). "La precarización del trabajo: ¿Premisa de la globalización?”. En: Papeles de Población, Universidad Autónoma del Estado de México, №. 18, Toluca, México: 82-98.

Sotelo, A. (1999). La precarización del trabajo en la economía global. Ediciones El Caballito, México. D.F.: 117-180.

Tokman, V. (2004). Una voz en el camino. Empleo y Equidad en América Latina, 40 años de búsqueda. Fondo de Cultura Económica, Santiago de Chile.

Waisgrais, S. (2001). "Trabajo decente en América Latina". En: Revista Latinoamericana de Estudios del Trabajo, 7 (14): 91-108.

Weller, J. (2000). Reformas económicas, crecimiento y empleo, los mercados de trabajo en América Latina durante los años noventa. Santiago de Chile, CEPAL/FCE.

Weller, J. (2006). "Problemas de la inserción laboral de la población juvenil en América Latina". En: Papeles de Población, Universidad Autónoma del Estado de México, №. 49, Toluca, México: 9-36.

Zavala-Cosío, E. \& Ojeda, N. (2011). "A manera de introducción: transiciones hacia la adultez en el contexto demográfico y social cambiante". En: Ojeda, N. \& Zavala-Cosío, E. (coord.). Jóvenes fronterizos/ Border Youth. Expectativas de vida familiar, educación y trabajo hacia la adultez. Primera edición. El Colegio de la Frontera Norte, Tijuana, México: 13-22. 


\section{ANEXO ESTADÍSTICO}

\section{1) Análisis factorial}

El objetivo de este anexo es presentar de manera detallada los resultados del análisis factorial a nivel nacional y de las tres ciudades para 2005 y 2010.

Tabla A.1. Pruebas de validez y confiabilidad del análisis factorial a nivel nacional y las tres ciudades, 2005 y $2010^{11}$

\begin{tabular}{|c|c|c|c|c|c|}
\hline \multirow{2}{*}{ Pruebas } & & \multicolumn{2}{|c|}{ Nacional } & \multicolumn{2}{|c|}{ Tres ciudades } \\
\hline & & 2005 & 2010 & 2005 & 2010 \\
\hline \multicolumn{2}{|c|}{ KMO of Sampling Adequacy. } & 0.84 & 0.849 & 0.833 & 0.835 \\
\hline \multirow{3}{*}{$\begin{array}{l}\text { Bartlett's Test of } \\
\text { Sphericity }\end{array}$} & $\begin{array}{l}\text { Approx. Chi- } \\
\text { Square }\end{array}$ & 108474.8 & 101661.1 & 6191.4 & 6088.272 \\
\hline & df & 21 & 21 & 21 & 21 \\
\hline & Sig. & 0 & 0 & 0 & 0 \\
\hline
\end{tabular}

Tabla A.2. Comunalidades de las varables, 2005 y $2010^{12}$

\begin{tabular}{lccccc}
\hline \multirow{2}{*}{ Indicador } & \multirow{2}{*}{ Initial } & \multicolumn{2}{c}{ Extraction, 2005 } & \multicolumn{2}{c}{ Extraction, 2010 } \\
\cline { 3 - 6 } \cline { 3 - 6 } & & Nacional & Tres ciudades & Nacional & Tres ciudades \\
\hline sal_min & 1 & 0.274 & 0.243 & 0.258 & 0.22 \\
temp_con & 1 & 0.679 & 0.651 & 0.696 & 0.67 \\
atencion_med & 1 & 0.78 & 0.804 & 0.776 & 0.811 \\
prestaciones_soc & 1 & 0.681 & 0.687 & 0.67 & 0.731 \\
jornada_comple & 1 & 0.994 & 0.947 & 0.854 & 0.95 \\
Sindicato & 1 & 0.207 & 0.15 & 0.364 & 0.137 \\
Contrato & 1 & 0.795 & 0.841 & 0.795 & 0.826 \\
\hline
\end{tabular}

Tabla A.3. Extracción de los factores a nivel nacional, $2005^{13}$

\begin{tabular}{|c|c|c|c|c|c|c|c|c|c|}
\hline \multirow{2}{*}{ Component } & \multicolumn{3}{|c|}{ Initial Eigenvalues } & \multicolumn{3}{|c|}{ Extraction Sums of Squared Loadings } & \multicolumn{3}{|c|}{ Rotation Sums of Squared Loadings } \\
\hline & Total & $\%$ of Variance & Cumulative $\%$ & Total & $\%$ of Variance & Cumulative \% & Total & $\%$ of Variance & Cumulative $\%$ \\
\hline 1 & 3.471 & 49.582 & 49.582 & 3.471 & 49.582 & 49.582 & 3.365 & 48.065 & 48.065 \\
\hline 2 & .938 & 13.402 & 62.984 & .938 & 13.402 & 62.984 & 1.044 & 14.919 & 62.984 \\
\hline 3 & .854 & 12.197 & 75.181 & & & & & & \\
\hline 4 & .796 & 11.378 & 86.559 & & & & & & \\
\hline 5 & .485 & 6.934 & 93.494 & & & & & & \\
\hline 6 & .261 & 3.734 & 97.228 & & & & & & \\
\hline 7 & .194 & 2.772 & 100.000 & & & & & & \\
\hline
\end{tabular}

11 Fuente: Elaboración propia con base en la ENOE, primeros trimestres de 2005 y 2010. INEGI.

12 Fuente: Elaboración propia con base en la ENOE, primeros trimestres de 2005 y 2010. INEGI.

13 Fuente: Elaboración propia con base en la ENOE, primeros trimestres de 2005 y 2010. INEGI. 
Tabla A.4. Extracción de las factores a nivel naconal, 2010.14

\begin{tabular}{|c|c|c|c|c|c|c|c|c|c|}
\hline \multirow{2}{*}{ Component } & \multicolumn{3}{|c|}{ Initial Eigenvalues } & \multicolumn{3}{|c|}{ Extraction Sums of Squared Loadings } & \multicolumn{3}{|c|}{ Rotation Sums of Squared Loadings } \\
\hline & Total & $\%$ of Variance & Cumulative \% & Total & $\%$ of Variance & Cumulative \% & Total & $\%$ of Variance & Cumulative $\%$ \\
\hline 1 & 3.450 & 49.292 & 49.292 & 3.450 & 49.292 & 49.292 & 3.433 & 49.037 & 49.037 \\
\hline 2 & .952 & 13.597 & 62.889 & .952 & 13.597 & 62.889 & .970 & 13.853 & 62.889 \\
\hline 3 & .855 & 12.216 & 75.106 & & & & & & \\
\hline 4 & .801 & 11.446 & 86.552 & & & & & & \\
\hline 5 & .462 & 6.597 & 93.149 & & & & & & \\
\hline 6 & .276 & 3.945 & 97.093 & & & & & & \\
\hline 7 & .203 & 2.907 & 100.000 & & & & & & \\
\hline
\end{tabular}

Tabla A.5. Extracción de las factores a nivel naconal, $2005^{15}$

\begin{tabular}{|c|c|c|c|c|c|c|c|c|c|}
\hline \multirow{2}{*}{ Component } & \multicolumn{3}{|c|}{ Initial Eigenvalues } & \multicolumn{3}{|c|}{ Extraction Sums of Squared Loadings } & \multicolumn{3}{|c|}{ Rotation Sums of Squared Loadings } \\
\hline & Total & $\%$ of Variance & Cumulative \% & Total & $\%$ of Variance & Cumulative \% & Total & $\%$ of Variance & Cumulative \% \\
\hline 1 & 3.336 & 47.659 & 47.659 & 3.336 & 47.659 & 47.659 & 3.316 & 47.379 & 47.379 \\
\hline 2 & .987 & 14.095 & 61.753 & .987 & 14.095 & 61.753 & 1.006 & 14.375 & 61.753 \\
\hline 3 & .927 & 13.250 & 75.003 & & & & & & \\
\hline 4 & .826 & 11.794 & 86.797 & & & & & & \\
\hline 5 & .471 & 6.733 & 93.530 & & & & & & \\
\hline 6 & .289 & 4.126 & 97.656 & & & & & & \\
\hline 7 & .164 & 2.344 & 100.000 & & & & & & \\
\hline
\end{tabular}

Tabla A.6. Extracción de las factores para las tres ciudades $2010^{16}$

\begin{tabular}{|c|c|c|c|c|c|c|c|c|c|}
\hline \multirow{2}{*}{ Component } & \multicolumn{3}{|c|}{ Initial Eigenvalues } & \multicolumn{3}{|c|}{ Extraction Sums of Squared Loadings } & \multicolumn{3}{|c|}{ Rotation Sums of Squared Loadings } \\
\hline & Total & $\%$ of Variance & Cumulative $\%$ & Total & $\%$ of Variance & Cumulative \% & Total & $\%$ of Variance & Cumulative $\%$ \\
\hline 1 & 3.365 & 48.069 & 48.069 & 3.365 & 48.069 & 48.069 & 3.253 & 46.472 & 46.472 \\
\hline 2 & .980 & 14.000 & 62.069 & .980 & 14.000 & 62.069 & 1.092 & 15.598 & 62.069 \\
\hline 3 & .936 & 13.369 & 75.438 & & & & & & \\
\hline 4 & .837 & 11.963 & 87.401 & & & & & & \\
\hline 5 & .453 & 6.469 & 93.870 & & & & & & \\
\hline 6 & .251 & 3.580 & 97.450 & & & & & & \\
\hline 7 & .178 & 2.550 & 100.000 & & & & & & \\
\hline
\end{tabular}

Tabla A.7. Matriz de componentes de los modelos, 2005 y $2010^{17}$

\begin{tabular}{|c|c|c|c|c|c|c|c|c|}
\hline \multirow{4}{*}{ Indicador } & \multicolumn{4}{|c|}{2005} & \multicolumn{4}{|c|}{2010} \\
\hline & \multicolumn{2}{|c|}{ Nacional } & \multicolumn{2}{|c|}{ Tres ciudades } & \multicolumn{2}{|c|}{ Nacional } & \multicolumn{2}{|c|}{ Tres ciudades } \\
\hline & \multicolumn{2}{|c|}{ Componente } & \multicolumn{2}{|c|}{ Componente } & \multicolumn{2}{|c|}{ Componente } & \multicolumn{2}{|c|}{ Componente } \\
\hline & 1 & 2 & 1 & 2 & 1 & 2 & 1 & 2 \\
\hline Contrato & 0.89 & -0.059 & 0.89 & -0.059 & 0.891 & -0.03 & 0.907 & -0.066 \\
\hline atencion_med & 0.882 & -0.044 & 0.882 & -0.044 & 0.881 & -0.007 & 0.9 & -0.023 \\
\hline prestaciones_soc & 0.824 & -0.041 & 0.824 & -0.041 & 0.818 & 0.007 & 0.853 & -0.05 \\
\hline temp_con & 0.82 & -0.084 & 0.82 & -0.084 & 0.832 & -0.06 & 0.812 & -0.105 \\
\hline sal_min & 0.518 & -0.076 & 0.518 & -0.076 & 0.507 & -0.015 & 0.462 & -0.081 \\
\hline Sindicato & 0.442 & -0.105 & 0.442 & -0.105 & 0.423 & -0.431 & 0.308 & -0.205 \\
\hline jornada_comple & 0.294 & 0.952 & 0.294 & 0.952 & 0.305 & 0.872 & 0.192 & 0.956 \\
\hline
\end{tabular}

14 Fuente: Elaboración propia con base en la ENOE, primeros trimestres de 2005 y 2010. INEGI.

15 Fuente: Elaboración propia con base en la ENOE, primeros trimestres de 2005 y 2010. INEGI.

16 Fuente: Elaboración propia con base en la ENOE, primeros trimestres de 2005 y 2010. INEGI

17 Fuente: Elaboración propia con base en la ENOE, primeros trimestres de 2005 y 2010. INEGI. 
Tabla A.8. Matriz rotada de los componentes de los modelos, 2005 y $2010^{18}$

\begin{tabular}{|c|c|c|c|c|c|c|c|c|}
\hline \multirow{4}{*}{ Indicador } & \multicolumn{2}{|c|}{ Nacional } & \multicolumn{2}{|c|}{ Tres ciudades } & \multicolumn{2}{|c|}{ Nacional } & \multicolumn{2}{|c|}{ Tres ciudades } \\
\hline & \multicolumn{4}{|c|}{2005} & \multicolumn{4}{|c|}{2010} \\
\hline & \multicolumn{2}{|c|}{ Component } & \multicolumn{2}{|c|}{ Component } & \multicolumn{2}{|c|}{ Component } & \multicolumn{2}{|c|}{ Component } \\
\hline & 1 & 2 & 1 & 2 & 1 & 2 & 1 & 2 \\
\hline contrato & 0.883 & 0.124 & 0.913 & 0.084 & 0.89 & 0.056 & 0.899 & 0.132 \\
\hline atencion_med & 0.872 & 0.137 & 0.893 & 0.077 & 0.877 & 0.078 & 0.884 & 0.172 \\
\hline temp_con & 0.819 & 0.086 & 0.823 & 0.093 & 0.834 & 0.02 & 0.815 & 0.073 \\
\hline prestaciones_soc & 0.815 & 0.128 & 0.807 & 0.01 & 0.814 & 0.086 & 0.844 & 0.136 \\
\hline sal_min & 0.523 & 0.031 & 0.489 & -0.062 & 0.506 & 0.033 & 0.469 & 0.021 \\
\hline sindicato & 0.454 & -0.012 & 0.332 & -0.202 & 0.462 & -0.389 & 0.056 & 0.266 \\
\hline jornada_comple & 0.093 & 0.993 & 0.083 & 0.97 & 0.22 & 0.897 & -0.02 & 0.974 \\
\hline
\end{tabular}

\section{2) Pruebas de hipótesis ${ }^{19}$}

El objetivo de este anexo es presentar de manera detallada los resultados de las pruebas de hipótesis para 2005 y 2010.

Hipótesis: Extremo y alto en Tijuana $Z$ Test for Differences in Two Proportions

\begin{tabular}{|l|r|}
\hline \multicolumn{2}{|c|}{ Data } \\
\hline Hypothesized Difference & 0 \\
\hline Level of Significance & 0.05 \\
\hline \multicolumn{2}{|c|}{ Group 1 } \\
\hline Number of Successes & 169 \\
\hline Sample Size & $\mathbf{7 1 0}$ \\
\hline \multicolumn{2}{|c|}{ Group 2 } \\
\hline Number of Successes & $\mathbf{2 2 5}$ \\
\hline Sample Size & $\mathbf{7 0 9}$ \\
\hline
\end{tabular}

\begin{tabular}{|l|r|}
\hline \multicolumn{2}{|c|}{ Intermediate Calculations } \\
\hline Group 1 Proportion & 0.238028169 \\
\hline Group 2 Proportion & 0.317348378 \\
\hline Difference in Two Proportion & -0.079320209 \\
\hline Average Proportion & 0.277660324 \\
\hline Z Test Statistic & $\mathbf{- 3 . 3 3 5 9 3 2 8 1 8}$ \\
\hline
\end{tabular}

\begin{tabular}{|l|c|}
\hline \multicolumn{2}{|c|}{ Lower-Tail Test } \\
\hline Lower Critical Value & -1.644853627 \\
\hline$p$-Value & 0.000425069 \\
\hline \multicolumn{2}{|c|}{ Do not reject the null hypothesis } \\
\hline
\end{tabular}

Hipótesis: Medio, bajo y no precario en Tijuana $Z$ Test for Differences in Two Proportions

\begin{tabular}{|l|r|}
\hline \multicolumn{2}{|c|}{ Data } \\
\hline Hypothesized Differenc & 0 \\
\hline Level of Significance & 0.05 \\
\hline \multicolumn{2}{|c|}{ Group 1 } \\
\hline Number of Successes & 472 \\
\hline Sample Size & 710 \\
\hline \multicolumn{2}{|c|}{ Group 2 } \\
\hline Number of Successes & 427 \\
\hline Sample Size & 709 \\
\hline
\end{tabular}

\begin{tabular}{|l|r|}
\hline \multicolumn{2}{|c|}{ Intermediate Calculations } \\
\hline Group 1 Proportion & 0.664788732 \\
\hline Group 2 Proportion & 0.6022567 \\
\hline Difference in Two Propor & 0.062532033 \\
\hline Average Proportion & 0.63354475 \\
\hline Z Test Statistic & $\mathbf{2 . 4 4 4 3 5 6 3 4 7}$ \\
\hline
\end{tabular}

\begin{tabular}{|l|r|}
\hline \multicolumn{2}{|c|}{ Lower-Tail Test } \\
\hline Upper Critical Value & 1.644853627 \\
\hline $\boldsymbol{p}$-Value & 0.007255543 \\
\hline \multicolumn{2}{|c|}{ Do not reject the null hypothesis } \\
\hline
\end{tabular}

Fuente: Elaboración propia con base en la ENOE, primeros trimestres de 2005 y 2010. INEGI.

19 Fuente: Elaboración propia con base en la ENOE Ph. 
Hipótesis: Nivel alto de empleo precario

Toluca-Mérica, 2005

Z Test for Differences in Two Proportions

\begin{tabular}{|l|r|}
\hline \multicolumn{2}{|c|}{ Data } \\
\hline Hypothesized Difference & 0 \\
\hline Level of Significance & $\mathbf{0 . 0 5}$ \\
\hline \multicolumn{2}{|c|}{ Group 1 } \\
\hline Number of Successes & $\mathbf{4 7}$ \\
\hline Sample Size & $\mathbf{7 9 9}$ \\
\hline \multicolumn{2}{|c|}{ Group 2 } \\
\hline Number of Successes & 109 \\
\hline Sample Size & $\mathbf{7 8 0}$ \\
\hline
\end{tabular}

\begin{tabular}{|l|r|}
\hline \multicolumn{2}{|c|}{ Intermediate Calculations } \\
\hline Group 1 Proportion & 0.058823529 \\
\hline Group 2 Proportion & 0.13974359 \\
\hline Difference in Two Proportion & -0.08092006 \\
\hline Average Proportion & 0.098796707 \\
\hline Z Test Statistic & $-\mathbf{5 . 3 8 7 6 9 7 5 1 3}$ \\
\hline
\end{tabular}

\begin{tabular}{|l|r|}
\hline \multicolumn{2}{|c|}{ Lower-Tail Test } \\
\hline Lower Critical Value & -1.644853627 \\
\hline$p$-Value & $3.5683 \mathrm{E}-08$ \\
\hline \multicolumn{2}{|c|}{ Do not reject the null hypothesis } \\
\hline
\end{tabular}

Hipótesis: Nivel alto de empleo precario Toluca-Mérica, 2010

Z Test for Differences in Two Proportions

\begin{tabular}{|l|r|}
\hline \multicolumn{2}{|c|}{ Data } \\
\hline Hypothesized Difference & 0 \\
\hline Level of Significance & 0.05 \\
\hline \multicolumn{2}{|c|}{ Group 1 } \\
\hline Number of Successes & 42 \\
\hline Sample Size & 717 \\
\hline \multicolumn{2}{|c|}{ Group 2 } \\
\hline Number of Successes & 141 \\
\hline Sample Size & 731 \\
\hline
\end{tabular}

\begin{tabular}{|l|r|}
\hline \multicolumn{2}{|c|}{ Intermediate Calculations } \\
\hline Group 1 Proportion & 0.058577406 \\
\hline Group 2 Proportion & 0.192886457 \\
\hline Difference in Two Proport & -0.134309051 \\
\hline Average Proportion & 0.126381215 \\
\hline Z Test Statistic & $\mathbf{- 7 . 6 9 0 1 8 9 1 2}$ \\
\hline
\end{tabular}

\begin{tabular}{|l|r|}
\hline \multicolumn{2}{|c|}{ Lower-Tail Test } \\
\hline Lower Critical Value & -1.644853627 \\
\hline$p$-Value & $7.34588 \mathrm{E}-15$ \\
\hline \multicolumn{2}{|c|}{ Do not reject the null hypothesis } \\
\hline
\end{tabular}

Hipótesis: Nivel alto de empleo precario

Toluca-Tijuana, 2010

Z Test for Differences in Two Proportions

\begin{tabular}{|l|r|}
\hline \multicolumn{2}{|c|}{ Data } \\
\hline Hypothesized Differenc & 0 \\
\hline Level of Significance & 0.05 \\
\hline \multicolumn{2}{|c|}{ Group 1 } \\
\hline Number of Successes & 42 \\
\hline Sample Size & 717 \\
\hline \multicolumn{2}{|c|}{ Group 2 } \\
\hline Number of Successes & 79 \\
\hline Sample Size & 709 \\
\hline
\end{tabular}

\begin{tabular}{|l|r|}
\hline \multicolumn{2}{|c|}{ Intermediate Calculations } \\
\hline Group 1 Proportion & 0.058577406 \\
\hline Group 2 Proportion & 0.111424542 \\
\hline Difference in Two Propor & -0.052847136 \\
\hline Average Proportion & 0.084852735 \\
\hline Z Test Statistic & -3.580683799 \\
\hline
\end{tabular}

\begin{tabular}{|l|r|}
\hline \multicolumn{2}{|c|}{ Lower-Tail Test } \\
\hline Lower Critical Value & -1.644853627 \\
\hline$p$-Value & 0.000171348 \\
\hline \multicolumn{2}{|c|}{ Do not reject the null hypothesis } \\
\hline
\end{tabular}

Hipótesis: Nivel alto de empleo precario

Toluca-Tijuana, 2005

Z Test for Differences in Two Proportions

\begin{tabular}{|c|c|}
\hline \multicolumn{2}{|c|}{ Data } \\
\hline Hypothesized Diffe & 0 \\
\hline Level of Significan & 0.05 \\
\hline \multicolumn{2}{|c|}{ Group 1} \\
\hline Number of Success & 47 \\
\hline Sample Size & 799 \\
\hline \multicolumn{2}{|c|}{ Group 2} \\
\hline Number of Success & 27 \\
\hline Sample Size & 710 \\
\hline
\end{tabular}

\begin{tabular}{|l|r|}
\hline \multicolumn{2}{|c|}{ Intermediate Calculations } \\
\hline Group 1 Proportion & 0.058823529 \\
\hline Group 2 Proportion & 0.038028169 \\
\hline Difference in Two Pr & 0.02079536 \\
\hline Average Proportion & 0.049039099 \\
\hline Z Test Statistic & $\mathbf{1 . 8 6 7 1 1 8 2 5 4}$ \\
\hline
\end{tabular}

\begin{tabular}{|l|r|}
\hline \multicolumn{2}{|c|}{ Upper-Tail Test } \\
\hline Upper Critical Valu & 1.644853627 \\
\hline$p$-Value & 0.030942538 \\
\hline \multicolumn{2}{|c|}{ Do not reject the null hypothesis } \\
\hline
\end{tabular}


Hipótesis: Nivel extremo de empleo precario Toluca-Mérica, 2005

Z Test for Differences in Two Proportions

\begin{tabular}{|l|r|}
\hline \multicolumn{2}{|c|}{ Data } \\
\hline Hypothesized Difference & $\mathbf{0}$ \\
\hline Level of Significance & $\mathbf{0 . 0 5}$ \\
\hline \multicolumn{2}{|c|}{ Group 1 } \\
\hline Number of Successes & $\mathbf{2 4 5}$ \\
\hline Sample Size & $\mathbf{7 9 9}$ \\
\hline \multicolumn{2}{|c|}{ Group 2 } \\
\hline Number of Successes & $\mathbf{2 1 0}$ \\
\hline Sample Size & $\mathbf{7 8 0}$ \\
\hline
\end{tabular}

\begin{tabular}{|l|r|}
\hline \multicolumn{2}{|c|}{ Intermediate Calculations } \\
\hline Group 1 Proportion & 0.306633292 \\
\hline Group 2 Proportion & 0.269230769 \\
\hline Difference in Two Proportion & 0.037402522 \\
\hline Average Proportion & 0.288157061 \\
\hline Z Test Statistic & $\mathbf{1 . 6 4 0 6 7 9 6 5 8}$ \\
\hline
\end{tabular}

\begin{tabular}{|l|r|}
\hline \multicolumn{2}{|c|}{ Lower-Tail Test } \\
\hline Lower Critical Value & -1.644853627 \\
\hline$p$-Value & $\mathbf{0 . 0 0 0 6}$ \\
\hline \multicolumn{2}{|c|}{ Do not reject the null hypothesis } \\
\hline
\end{tabular}

Hipótesis: Nivel extremo de empleo precario Toluca-Mérica, 2010

Z Test for Differences in Two Proportions

\begin{tabular}{|l|r|}
\hline \multicolumn{2}{|c|}{ Data } \\
\hline Hypothesized Differenc & 0 \\
\hline Level of Significance & 0.05 \\
\hline \multicolumn{2}{|c|}{ Group 1 } \\
\hline Number of Successes & 259 \\
\hline Sample Size & 717 \\
\hline \multicolumn{2}{|c|}{ Group 2 } \\
\hline Number of Successes & 185 \\
\hline Sample Size & 731 \\
\hline
\end{tabular}

\begin{tabular}{|l|r|}
\hline \multicolumn{2}{|c|}{ Intermediate Calculations } \\
\hline Group 1 Proportion & 0.361227336 \\
\hline Group 2 Proportion & 0.253077975 \\
\hline Difference in Two Proport & 0.108149361 \\
\hline Average Proportion & 0.306629834 \\
\hline Z Test Statistic & 4.462396564 \\
\hline
\end{tabular}

\begin{tabular}{|l|r|}
\hline \multicolumn{2}{|c|}{ Lower-Tail Test } \\
\hline Lower Critical Value & -1.644853627 \\
\hline$p$-Value & 0.0098678 \\
\hline \multicolumn{2}{|c|}{ Do not reject the null hypothesis } \\
\hline
\end{tabular}

Hipótesis: Nivel extremo de empleo precario Toluca-Tijuana, 2010

Z Test for Differences in Two Proportions

\begin{tabular}{|l|r|}
\hline \multicolumn{2}{|c|}{ Data } \\
\hline Hypothesized Differenc & 0 \\
\hline Level of Significance & 0.05 \\
\hline \multicolumn{2}{|c|}{ Group 1 } \\
\hline Number of Successes & 259 \\
\hline Sample Size & 717 \\
\hline \multicolumn{2}{|c|}{ Group 2 } \\
\hline Number of Successes & 146 \\
\hline Sample Size & 709 \\
\hline
\end{tabular}

\begin{tabular}{|l|r|}
\hline \multicolumn{2}{|c|}{ Intermediate Calculations } \\
\hline Group 1 Proportion & 0.361227336 \\
\hline Group 2 Proportion & 0.205923836 \\
\hline Difference in Two Propor & 0.1553035 \\
\hline Average Proportion & 0.28401122 \\
\hline Z Test Statistic & 6.502544278 \\
\hline
\end{tabular}

\begin{tabular}{|l|r|}
\hline \multicolumn{2}{|c|}{ Lower-Tail Test } \\
\hline Lower Critical Value & -1.644853627 \\
\hline$p$-Value & 0.000478 \\
\hline \multicolumn{2}{|c|}{ Do not reject the null hypothesis } \\
\hline
\end{tabular}

Hipótesis: Nivel alto de empleo precario Toluca-Tijuana, 2005

Z Test for Differences in Two Proportions

\begin{tabular}{|c|c|}
\hline \multicolumn{2}{|c|}{ Data } \\
\hline Hypothesized Diffe & 0 \\
\hline Level of Significan & 0.05 \\
\hline \multicolumn{2}{|c|}{ Group 1} \\
\hline Number of Success & 245 \\
\hline Sample Size & 799 \\
\hline \multicolumn{2}{|c|}{ Group 2} \\
\hline Number of Success & 146 \\
\hline Sample Size & 710 \\
\hline
\end{tabular}

\begin{tabular}{|l|r|}
\hline \multicolumn{2}{|c|}{ Intermediate Calculations } \\
\hline Group 1 Proportion & 0.306633292 \\
\hline Group 2 Proportion & 0.205633803 \\
\hline Difference in Two Pr & 0.100999489 \\
\hline Average Proportion & 0.259111995 \\
\hline Z Test Statistic & $\mathbf{4 . 4 6 9 4 8 0 8 3 2}$ \\
\hline
\end{tabular}

\begin{tabular}{|l|c|}
\hline \multicolumn{2}{|c|}{ Upper-Tail Test } \\
\hline Upper Critical Valu & 1.644853627 \\
\hline$p$-Value & $3.92048 \mathrm{E}-06$ \\
\hline \multicolumn{2}{|c|}{ Do not reject the null hypothesis } \\
\hline
\end{tabular}

